\title{
Comparative bioclimatic approach for comfort and passive heating and cooling strategies in Algeria
}

\author{
Samir Semahi ${ }^{\mathrm{a}, \mathrm{b}, \mathrm{d}}$, Noureddine Zemmouri ${ }^{\mathrm{b}}$, Manoj Kumar Singh ${ }^{\mathrm{c}}$, Shady Attia ${ }^{\mathrm{d}, *}$ \\ ${ }^{a}$ Institute of Architecture and Urbanism, University of Blida-1, Blida, Algeria \\ ${ }^{\mathrm{b}}$ Laboratory of Design and Modeling of Architectural and Urban Forms and Ambiances (LACOMOFA), Department of Architecture, University of Biskra, Biskra, Algeria \\ ${ }^{\mathrm{c}}$ Department of Human and Social Systems, Institute of Industrial Science, The University of Tokyo, 4-6-1, Komaba, Meguro-ku, Tokyo, 153-8505, Japan \\ ${ }^{\mathrm{d}}$ Sustainable Building Design Lab, Dept UEE Applied Sciences, Universite de Liege, Belgium
}

\section{A R T I C L E I N F O}

\section{Keywords:}

Climate analysis

Bioclimatic chart

Adaptive comfort

Bioclimatic design

Energy simulation

Residential building

\begin{abstract}
A B S T R A C T
The energy consumption and thermal comfort in buildings are heavily affected by weather conditions. Therefore, the aim of this paper is to analyze the bioclimatic potential of Algerian climate zones. This analysis was made based on eight representative locations using recent weather datasets (2003-2017). The thermal comfort and passive design potential analysis were based on a psychometric chart applying the adaptive comfort model ASHRAE 55-2017. In addition, an evaluation of the bioclimatic potential was conducted using simulations of a monitored and calibrated residential building model in Algeria using EnergyPlus. The building model has been tested in eight previously selected locations. The heating and cooling energy load results were calculated for each climatic zone and compared. The results allow architects and urban planners to better understand the climate and provide practical design guidance.
\end{abstract}

\section{Introduction}

The present and future of sustainably built environments is influenced by the ability of architects, engineers, and urban designers to create buildings that reduce building-associated carbon dioxide emissions and at the same time achieve high levels of thermal comfort [1]. However, this ability is influenced by the understanding of the local climate and the application of corresponding bioclimatic design principles and strategies [2]. In the past, many innovative heating, ventilation, and air conditioning (HVAC) technologies have been proposed to improve the indoor conditions, regardless of energy savings. Today, the integration of passive and active design solutions in newly constructed buildings is becoming a must worldwide. The recent progress with respect to adaptive thermal comfort models and their proliferation influence our understanding of the bioclimatic building performance [3-5]. Therefore, bioclimatic studies that investigate the effects of climate on the thermal comfort conditions and the building heating and cooling energy demand are increasingly receiving attention from the research and development community [6-8].

Integrating bioclimatic analysis tools into daily urban or architectural design practices is a challenge but an essential step towards realizing effective climate-responsive design [8]. Several analytical tools are available for the quantification of the potential effectiveness of design strategies, e.g., the ECOTECT Weather Tool [9] and Climate Consultant $[10,11]$. However, most of those analytical tools depend on static comfort models of fully space-conditioned buildings and are not suitable for buildings in hot climates [8]. More importantly, some of them lack sensitivity to hot climates and provide misleading design recommendations $[7,8,12,13]$. Providing accurate bioclimatic design recommendations is essential for making informed design decisions in early design stages $[14,15]$.

In this paper, we adopt a dual approach that combines psychrometric chart-based analysis with building performance simulation analysis for the development of accurate bioclimatic design recommendations for Algeria. This research approach is inspired by and builds on the work of Kumar et al. and Kishore et al. [16,17] and adds up on to it. Our research approach integrates the ASHRAE-55 adaptive comfort model as a novel assessment component. The main aim of this paper is to analyze the bioclimatic potential of passive design strategies in Algeria. The paper has two objectives:

1 Evaluate the thermal comfort and bioclimatic design potential of eight selected cities, which represent the six official climate zones of Algeria, based on a psychometric chart and the adaptive comfort model ASHRAE 55-2017.

2 Validate the bioclimatic potential analysis by simulating the heating

\footnotetext{
* Corresponding author.

E-mail address: shady.attia@uliege.be (S. Attia).
} 


\author{
Abbreviations \\ ASHRAE American Society of Heating, Refrigerating, and Air- \\ Conditioning Engineers \\ CNERIB Centre National d'Etudes et de Recherches Integrees du \\ Batiment \\ CV (RMSE) Coefficient of Variation or Root-Mean-Square Error \\ DBT Dry-Bulb Temperature \\ DEC Direct Evaporative Cooling
}
DHW
DTR
Domestic Hot Water
MBE Mean Bias Error
NV Natural Ventilation
PSH Passive Solar Heating
TMY Typical Meteorological Year
WBT Wet-Bulb Temperature
WWR Window-to-Wall Ratio

and cooling energy loads of a calibrated residential building for the eight selected cities.

The value of the paper is based on providing a systematic and methodological approach to assess the bioclimatic design potential in Algerian cities based on updated weather datasets. Validated bioclimatic design recommendations for comfort and passive heating and cooling in Algeria are obtained by using a recent dataset (2003-2017) of eight Algerian cities and a calibrated reference building for building performance simulation.

The paper is organized as follows. A literature is provided in Section 2. The research methodology and analysis results are described in detail in Sections 3 and 4. Section 5 reflects on the results of the reference case simulation and provides a critical discussion of the study's strength, limitations, and future implications. The paper is concluded in Section 6 by highlighting the key findings and contributions of the study.

\section{Literature review}

The importance of bioclimatic studies is growing and gaining momentum every year. The aim of bioclimatic studies is to understand the climate to maximize the benefits of bioclimatic building design strategies and ensure thermal comfort and increase the energy efficiency. Although being one of the most important aspects of building energy efficiency, several advances have been made in this field in recent years. Our literature review included more than 140 publications, found on Scopus and the Web of Science, relevant to the field of bioclimatic analysis. However, we selected the most relevant publications and classified them into groups using three main categories, which are described in the following paragraphs.

The first group of studies regarding bioclimatic analysis contains the oldest publications that relied on using bioclimatic charts to assess the climate and provide design recommendations for designers. The building bioclimatic chart indicates if the temperature and humidity conditions are within the comfort range of a building designed to effectively benefit from bioclimatic design strategies [18]. The most important publications of this group based on charts 1) are Mollier's psychrometric chart (1923), 2) Olgyay's chart (1963), and 3) Dekay and Browns chart (2004) [19-21].

The chart of Mollier is the one that is most famous and widely used by engineers, architects, and urban planners [16]. The chart evolved and benefited from the significant contributions of Givoni and Milne in 1979 that combined different bioclimatic design strategies in a chart [22]. In the same year, Milne developed an interactive computer-aided tool for passive solar design that later became the Climate Consultant program [23]. In the 1980s and 1990s, several researchers contributed to the psychrometric chart and applied unique comfort models [24]. More recently, several researchers applied the psychrometric chart to local contexts [25-28]. The chart of Olgyay has been used less because it is less comprehensive. However, several researchers applied it and validated its outcomes in the last years. The work of Katafygiotou et al. [29] on Cyprus and Pajek et al. [30] on Slovenia have recently become two of the most cited publications. The third type of chart that was published in 2004 by Dekay and Brown has been used in recent research in Australia, Iran, and Madagascar [8,11,31,32]. Unfortunately, bioclimatic charts lack sensitivity to hot climates and provide misleading design recommendations $[15,16]$.

The second group of studies regarding bioclimatic analysis mainly relies on building performance simulations to assess the climate and provide recommendations for designers. The building performance simulation (BPS) is the replication of aspects of the building performance using a computer-based, mathematical model created on the basis of fundamental physical principles and sound engineering practice [33]. This group is characterized by an abundance of publications worldwide. Therefore, we focused on the publications most relevant to Algeria, which aimed to calculate the bioclimatic potential or heating/cooling degree days or run simulations to predict the impact of climate change. This includes the work of Khouki et al. [34] who assessed the effectiveness of bioclimatic design strategies in hot dry regions of Algeria and that of Imessad et al. [35] who focused on assessing the effectiveness of passive cooling in Algiers. Among those studies, the study of Ghedamsi et al. [36] is the most relevant and comprehensive study in which the annual heating and cooling requirements of buildings in different regions of Algeria were calculated using the degree days method. Unfortunately, none of those studies followed a comprehensive approach that covers all climatic regions of Algeria while providing validated bioclimatic design recommendations that designers can apply in early design stages. More importantly, most studies that follow the simulation-based approach are post-design evaluations and mainly consider only hypothetical non-bioclimatic comfort models and thus do not validate early-design bioclimatic recommendations.

The third group of studies regarding bioclimatic analysis mainly relies on a mixed approach combing bioclimatic charts and building performance simulations to assess the climate and provide recommendations for designers. This group of studies emerged in 2017 with the work of Pajek et al. [12] who investigated the climatic potential of five cities in Slovenia and the work of Ali-Toudert et al. [37] who focused on two climatic zones in Algeria. The work of Kumar et al. and Kishore et al. [16,17] also belong to this group because they systematically combined bioclimatic chart analysis with building performance analysis for India. The advantage of the mixed approach is that it allows comparing the simulation results with the bioclimatic potential analysis to validate the design recommendation. More importantly, validated design recommendations are grouped and classified in a comprehensive way based on this approach, which contributes to the consolidation of the knowledge of bioclimatic design on national scales.

This overview and classification of literature demonstrate that the mixed bioclimatic analysis approach should be adopted to obtain information about the design of bioclimatic buildings. The literature review indicates that this mixed bioclimatic analysis approach has been the most studied approach in recent years, particularly in Algeria. Thus, the lack of validated design recommendations for bioclimatic design may inhibit the integration of bioclimatic design solutions and technologies in future buildings.

In this paper, we present the results of the application of a mixed approach that combines bioclimatic analysis and building performance simulations to address several of the points mentioned above. More specifically, the validity of bioclimatic design strategies in Algeria was 
tested based on a recent weather dataset (2003-2017), adaptive comfort model, and calibrated reference study.

\section{Materials and methods}

The research methodology is based on a comparative approach that quantifies the bioclimatic potential of different locations in Algeria using recent weather datasets. Firstly, the annual bioclimatic potential is quantified using simple psychrometric charts without considering the building effect. Secondly, a simulation model for a representative case study in Algeria is used to assess the bioclimatic potential including the building effect. Our methodology is inspired by the work of Khambadkone and Jain [38] who applied this approach in India. We applied their methodology to a new context. Fig. 1 presents the detailed conceptual framework of the study describing the steps of the research methodology. The conceptual framework of this study can be divided into four major steps. Each step is described in detail in the following sections.

\subsection{Literature review}

A literature review was conducted including recent publications that aimed to assess the bioclimatic potential worldwide. The publications included scientific manuscripts that focus on climate zoning and bioclimatic design. Our initial Scopus and Web of Science research resulted in more than 140 publications relevant to bioclimatic analysis. We then narrowed the research scope to focus on bioclimatic analysis in hot and hot-arid climates. The publication information was imported to the software HistCite for analysis and grouped into three categories: bioclimatic chart-based analysis, building performance simulation- based analysis, and mixed analysis. Moreover, a review of Algerian national standards and codes was performed to cover the local state of the art and reflect the regulation landscape. The results of the literature review are presented in Section 2.

\subsection{Selection of representative locations}

According to the Algerian National Center of Studies and Researches Integrees of the Building (CNERIB: Centre National d'Etudes et de Recherches Integrees du Batiment) and the thermal regulation (DTR C32) [39] for residential buildings, Algeria has six distinguished climatic zones: Zone (A): in the north of Algeria, including the coastal zone; Zone (B): in the south of zone (A), including the plain behind the seashore; Zone (C): in the south of zone (B), including the highlands; Zone (D): in the south of Algeria, including the desert; and the climate zones $\left(B^{\prime}\right)$ and $\left(D^{\prime}\right)$, representing subzones within the main zones (B) and (D), respectively. Some of the characteristics of the subzones differ from those of the main zones. For example, they have the same characteristics in winter as the main zones, but they are very hot in summer compared with the main zones (B) and (D). For our investigation, we selected eight locations because climate zone (D) covers a large area in the south of Algeria and we thus added two weather stations to this zone (see Table 1). Among those weather stations, we distinguished in Guezzam city, located in the south of Tamanrasset Region, because it has specific climatic characteristics. In Guezzam has an annual global radiation that exceeds $7600 \mathrm{Wh} / \mathrm{m}^{2}$ [40]. This could have an impact on other climate data for this location. We also used a map with the official climatic zones of Algeria. Fig. 2 indicates the locations of the eight selected weather stations.

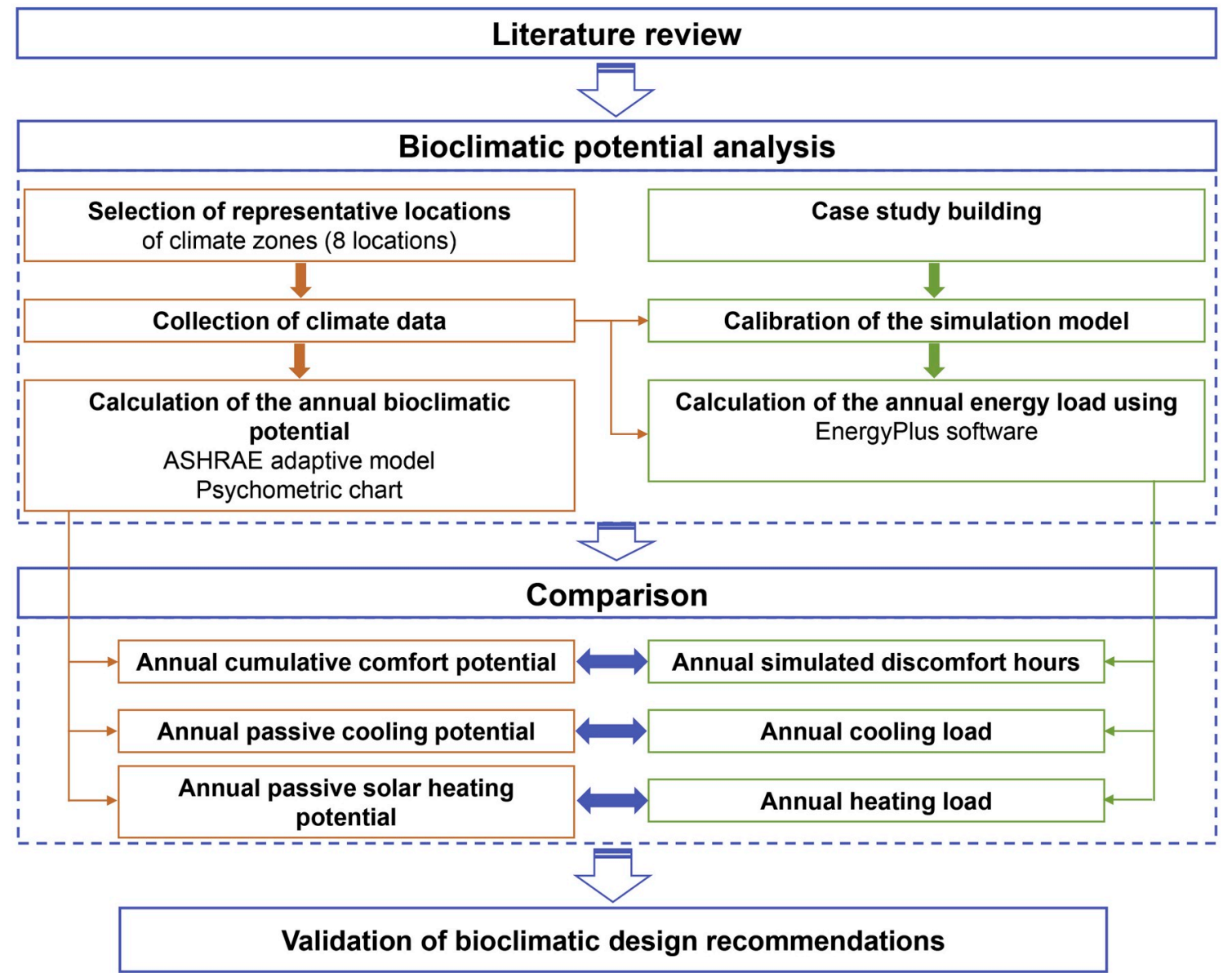

Fig. 1. Conceptual framework of this study. 
Table 1

Geographical information about the eight selected representative locations in Algeria.

\begin{tabular}{|c|c|c|c|c|c|}
\hline No. & Name of location & Station code & Coordinates & Altitude (m) & Climate zone (CNERIB classification) \\
\hline 1 & Algiers & $\mathrm{AL}$ & $36.6^{\circ} \mathrm{N} 3.2^{\circ} \mathrm{E}$ & 25 & A \\
\hline 2 & Guelma & GL & $36.4^{\circ} \mathrm{N} 7.4^{\circ} \mathrm{E}$ & 228 & B \\
\hline 3 & Chlef & $\mathrm{CH}$ & $36.2^{\circ} \mathrm{N} 1.3^{\circ} \mathrm{E}$ & 141 & $\mathrm{~B}^{\prime}$ \\
\hline 4 & Setif & SF & $36.1^{\circ} \mathrm{N} 5.3^{\circ} \mathrm{E}$ & 1050 & $\mathrm{C}$ \\
\hline 5 & Biskra & BS & $34.7^{\circ} \mathrm{N} 5.7^{\circ} \mathrm{E}$ & 88 & $\mathrm{D}$ \\
\hline 6 & Bechar & $\mathrm{BC}$ & $31.6^{\circ} \mathrm{N} 2.2^{\circ} \mathrm{W}$ & 811 & $\mathrm{D}$ \\
\hline 7 & Adrar & $\mathrm{AR}$ & $27.8^{\circ} \mathrm{N} 0.1^{\circ} \mathrm{W}$ & 280 & $\mathrm{D}^{\prime}$ \\
\hline 8 & Tamanrasset (in Guezzam) & TM & $19.6^{\circ} \mathrm{N} 5.8^{\circ} \mathrm{E}$ & 400 & $\mathrm{D}$ \\
\hline
\end{tabular}

\subsection{Climate data}

In this study, recent weather datasets (2003-2017) for eight locations were used. The last version of the Typical Meteorological Year (TMY) hourly weather data files for the eight selected locations was used (see Table 1). These weather data were created by the Algerian National Meteorology Office and made available by the United States Department of Energy [41].

\subsection{Calculation of annual bioclimatic potential}

A psychrometric chart and the adaptive comfort model ASHRAE 55-2017 were used to calculate the bioclimatic potential of the eight selected locations. The selection of the ASHRAE 55-2017 adaptive comfort model was based on the recommendations of Attia et al. [8] who consider it as the best available socioeconomic model that sets no humidity limit, which is essential in the coastal cities of Algeria.

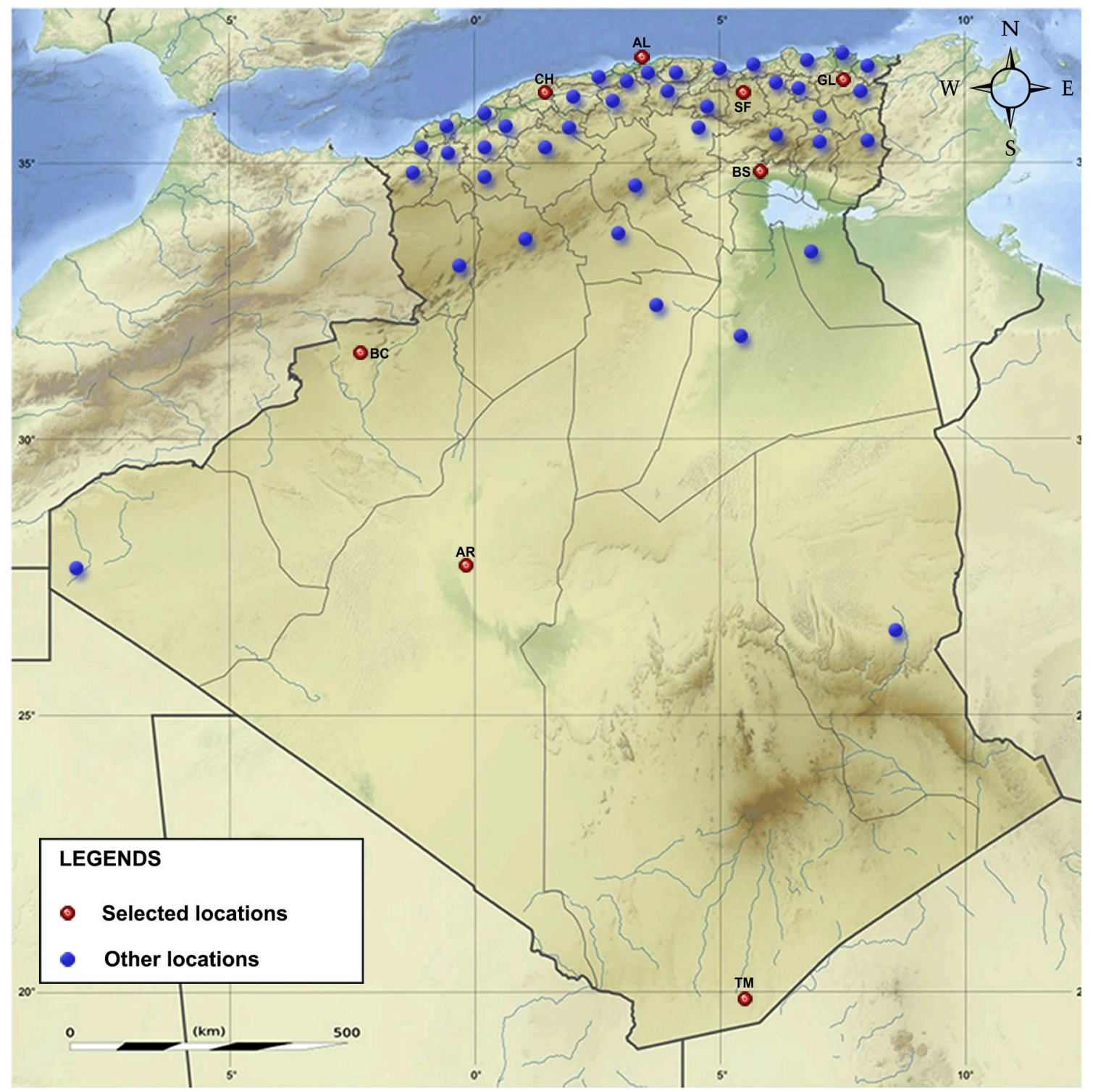

Fig. 2. Algerian map showing the eight selected locations. 
The hourly weather data of each location were plotted on the psychrometric chart. The data plots were created using three major bioclimatic design strategies or combinations of the three strategies:

- Passive Solar Heating (PSH)

- Natural Ventilation (NV)

- Direct Evaporative Cooling (DEC)

The literature review indicated that the three strategies listed above are the most effective design strategies, which are suitable for the climate of Algeria and should be prioritized by designers [34,42]. The boundaries of the thermal comfort zone were limited by the comfort temperature calculated by the adaptive comfort model ASHRAE 55-2017. The zone of direct evaporative cooling was limited by the thermal comfort zone. The wet-bulb temperature (WBT) maximum in summer is $\sim 24^{\circ} \mathrm{C}$ and the Dry Bulb Temperature (DBT) maximum is about $44^{\circ} \mathrm{C}$ (in hot-dry developing countries) according to Givoni [43]. The potential of thermal comfort, passive cooling, and passive heating were calculated based on the number of hourly data points within each boundary on the chart. The passive solar heating zone is a function of the building design. The lower limit of this zone is defined by the lowest outdoor air temperature at which the available solar radiation will produce minimum comfort temperatures. The bioclimatic chart for the eight selected locations was created based on these assumptions. Eqs (1) and (2) provide the basis of the bioclimatic potential calefactions:

- Optimal comfort temperature $\left({ }^{\circ} \mathrm{C}\right)[5,11]$ :

$T_{c}=0.31 f\left(T_{\text {out }}\right)+17.810{ }^{\circ} \mathrm{C} \leq f\left(T_{\text {out }}\right) \leq 33.5^{\circ} \mathrm{C}$

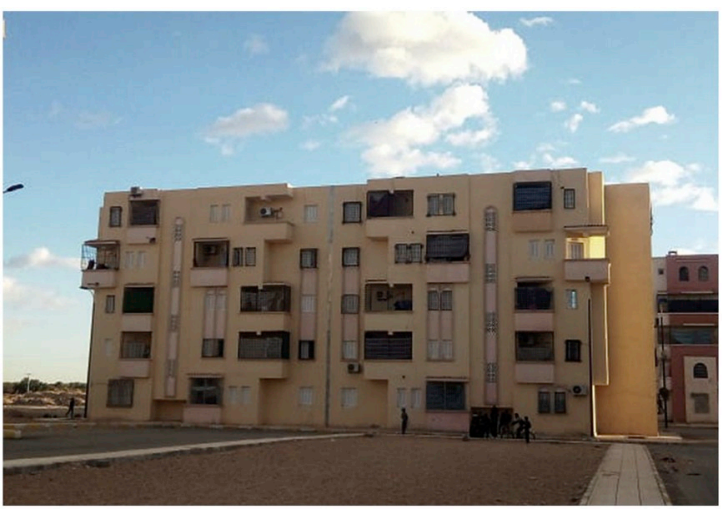

(a)

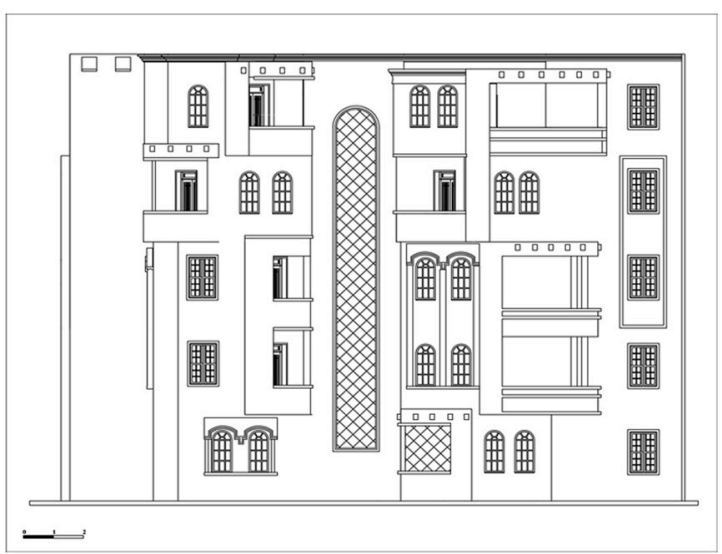

(c)
Upper $90 \%$ acceptability limit $\left({ }^{\circ} \mathrm{C}\right)$ :

$T_{c}=0.31 f\left(T_{\text {out }}\right)+20.310{ }^{\circ} \mathrm{C} \leq f\left(T_{\text {out }}\right) \leq 33.5^{\circ} \mathrm{C}$

Lower $90 \%$ acceptability limit $\left({ }^{\circ} \mathrm{C}\right)$ :

$T_{c}=0.31 f\left(T_{\text {out }}\right)+15.310{ }^{\circ} \mathrm{C} \leq f\left(T_{\text {out }}\right) \leq 33.5^{\circ} \mathrm{C}$

where $f\left(T_{\text {out }}\right)$ is the prevailing mean outdoor air temperature ( $\left.t_{\text {pma(out }}\right)$ in ASHRAE 55 for 2013 and 2017 and the mean monthly outdoor air temperature in ANSI/ASHRAE 55 for 2004 and 2010.

- Prevailing mean outdoor air temperature $\left({ }^{\circ} \mathrm{C}\right)[5]$ :

$t_{\text {pma(out) }}=(1-\alpha)\left[t_{e(d-1)}+\alpha \cdot t_{\text {e (d-2) }}+\alpha^{2} \cdot t_{\text {e (d-3) }}+\alpha^{4} \cdot t_{\text {e (d-4) }}+\ldots\right]$,

where $\alpha$ is a constant ranging between 0 and 1 and $t_{e}(d-1)$ is the daily mean external air temperature at time $d$ of a series of equal intervals (day).

In the last two versions, ANSI/ASHRAE 55 suggests an $\alpha$ value of 0.9 for climates in which the day-to-day temperature variation is relatively minor, such as the humid tropics, and a lower $\alpha$ value of 0.6 for midlatitude climates in which the day-to-day temperature variation is more pronounced.

\subsection{Reference building}

A representative reference building was selected to conduct building performance simulations. The case study includes a multi-family social housing typology in Biskra in the southwest of Algeria (coordinates:

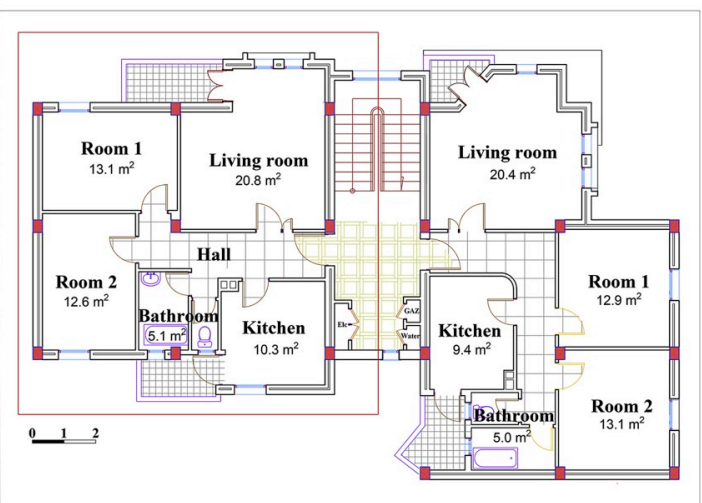

(b)

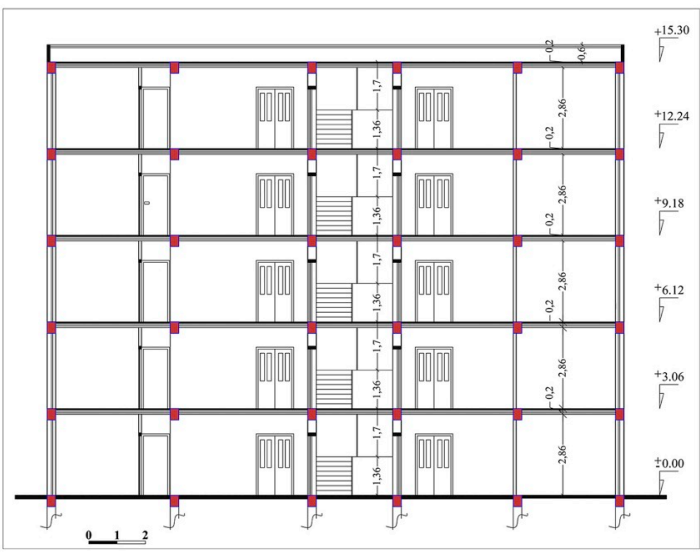

(d)

Fig. 3. Details of the selected multi-family social housing building typology; (a) real view of the building, (b) floor plan, (c) section, (d) front façade. 
$34^{\circ} 51^{\prime} \mathrm{N} 5^{\circ} 44^{\prime} \mathrm{E}$; altitude: $87 \mathrm{~m}$; Biskra, Latin Vescera). Biskra's climate is classified as hot desert climate and falls in zone BWh in the Köppen climate classification. This typology was chosen because it represents the most common typology in Algeria. The selected apartment was in the first floor to be more representative because the ground floor and highest floor are more affected by the outdoor environment. In addition, we were able to take real measurements in this apartment. Fig. 3 shows the characteristics of the reference building, which is a housing typology commonly found in most urban dense cities in Algeria. Table 2 presents the thermophysical properties of the building elements according to the Algerian Thermal Regulation of Residential Buildings [39].

\subsection{Simulation model and validation}

The reference building was modeled using EnergyPlus v.8.3 software, which is a validated program for the simulation of the building thermal performance [45]. Fig. 4 shows the 3D model of the reference building. The building geometry (see Fig. 3) and thermal properties of the real building components (Table 2) were used as the simulation model input. The systems of heating, cooling, and Domestic Hot Water (DHW) were represented based on a building audit, similar to the schedules of occupancy, lighting, heating, cooling, and DHW (see Fig. A). The TMY hourly weather data file for Biskra was used to represent the outdoor weather conditions. The following two sections describe the performance monitoring that was conducted for the reference building and the use of the monitoring data to validate the model.

\subsubsection{Building audit and monitoring}

The indoor air temperature and energy consumption of the selected apartment were monitored during 2016. A walkthrough visit was performed to identify the major energy use equipment (e.g., heating systems, air conditioners, ceiling fans, lighting, water heaters, stoves) and questions were asked about the living habits of the occupants to create occupancy and other related schedules. The indoor air temperatures were continuously recorded from January 21-27, 2016, (168 h) in the winter period and from July 12-18, 2016, (168 h) in the summer period. The indoor air temperatures were determined every hour with a Testo-480 measurement kit. We used the sensor temperature and humidity. The measurement range is $-20{ }^{\circ} \mathrm{C}$ to $+70{ }^{\circ} \mathrm{C}$ at an accuracy of $\pm 0.5{ }^{\circ} \mathrm{C}$. The instrument was installed in the living room. The measurements taken in the main living space of the apartment are considered representative, similar to the work of Colton et al. [46] and Lai et al. [47]. To avoid data distortion due to radiation from floor and walls, the instrument was placed in the center of the space at a height of $1.4 \mathrm{~m}$, which is the medium clear height of the living room. The monthly electric and gas consumptions $(\mathrm{kWh})$ were registered during 2016; the data were collected from electricity and gas meters.

\subsubsection{Calibration method}

The calibration focused on how closely the simulated results match the monitored data. The calibration was an essential step to allow the creation of a reliable simulation model. The simulation model was calibrated using the present building physics conditions and patterns of energy use. To calibrate the building simulation model, ASHRAE Guideline 14 was followed. Two indices of the ASHRAE Guildine 14 were used for our manual calibration: 1) mean bias error (MBE), and 2) coefficient of variation or root-mean-square error [CV (RMSE)]. The MBE is a nondimensional measure of the overall bias error between the measured and simulated data with a known time resolution. The CV (RMSE) indicates how well the simulation model describes the variability in the measured data. The MBE and CV (RMSE) values were calculated using the following equations:

$$
\begin{aligned}
& M B E=\frac{\sum_{i=1}^{N p}(M i-S i)}{\sum_{i=1}^{N p} M i}(\%) \\
& C V(R M S E)=\frac{1}{M} \sqrt{\frac{\sum_{i=1}^{N p}(M i-S i)^{2}}{N p}}(\%),
\end{aligned}
$$

where $\mathrm{Mi}$ and $\mathrm{Si}$ are the measured and simulated data at time interval $I$ and $N p$ is the total number of data values used for the calculation.

According to ASHRAE Guideline 14 [48], the simulation model is considered calibrated if:

- hourly MBE values are within $\pm 10 \%$ and hourly CV (RMSE) values are below $30 \%$

- monthly MBE values are within $\pm 5 \%$ and monthly CV (RMSE) values are below $15 \%$

The simulation was calibrated using two data categories: 1) hourly indoor temperature, and 2) monthly energy consumption. Each data

Table 2

\begin{tabular}{|c|c|c|c|c|c|c|c|c|}
\hline $\mathrm{N}^{\circ}$ & $\begin{array}{l}\text { Building } \\
\text { element }\end{array}$ & $\begin{array}{l}\text { Outside to } \\
\text { inside }\end{array}$ & Composition & Thickness (m) & $\begin{array}{l}\text { Thermal conductivity (W/ } \\
\mathrm{m}-\mathrm{K} \text { ) }\end{array}$ & $\begin{array}{l}\text { Density (kg/ } \\
\mathrm{m} 3)\end{array}$ & $\begin{array}{l}\text { Specific heat capacity } \\
(\mathrm{kJ} / \mathrm{kg} \mathrm{K})\end{array}$ & $\begin{array}{l}\text { U-value (W/ } \\
\mathrm{m} 2-\mathrm{K})\end{array}$ \\
\hline \multirow[t]{4}{*}{1} & \multirow[t]{4}{*}{ Exterior wall } & Layer 1 & Mortar & 0.02 & 1.15 & 1900 & 1.08 & \multirow[t]{4}{*}{1.118} \\
\hline & & Layer 2 & Hollow brick & 0.15 & 0.48 & 900 & 0.93 & \\
\hline & & Layer 4 & Hollow brick & 0.1 & 0.48 & 900 & 0.93 & \\
\hline & & Layer 5 & Plaster & 0.02 & 0.35 & 800 & 0.93 & \\
\hline 2 & Partition wall & Layer 1 & Plaster & 0.02 & 0.35 & 800 & 0.93 & 1.857 \\
\hline \multirow{3}{*}{3} & \multirow{3}{*}{ Internal floor } & Layer 2 & Mortar & 0.03 & 1.15 & 1900 & 1.08 & \multirow{3}{*}{1.985} \\
\hline & & Layer 3 & $\begin{array}{l}\text { Concrete slab (hollow } \\
\text { block) }\end{array}$ & 0.2 & 1.45 & 1450 & 1.08 & \\
\hline & & Layer 4 & Plaster & 0.02 & 0.35 & 800 & 0.93 & \\
\hline \multirow[t]{3}{*}{4} & \multirow[t]{3}{*}{ Roof } & Layer 1 & Tightness & 0.015 & 0.7 & 2100 & 1.04 & \multirow[t]{3}{*}{0.584} \\
\hline & & Layer 2 & Mortar & 0.04 & 1.15 & 1900 & 1.08 & \\
\hline & & Layer 3 & Polystyrene & 0.05 & 0.04 & 20 & 1.4 & \\
\hline 5 & Ground floor & Layer 3 & Tiling & 0.02 & 1.7 & 2200 & 0.93 & 3.259 \\
\hline
\end{tabular}

Thermal properties of the building elements of the selected multi-family social housing typology $[39,44]$. 


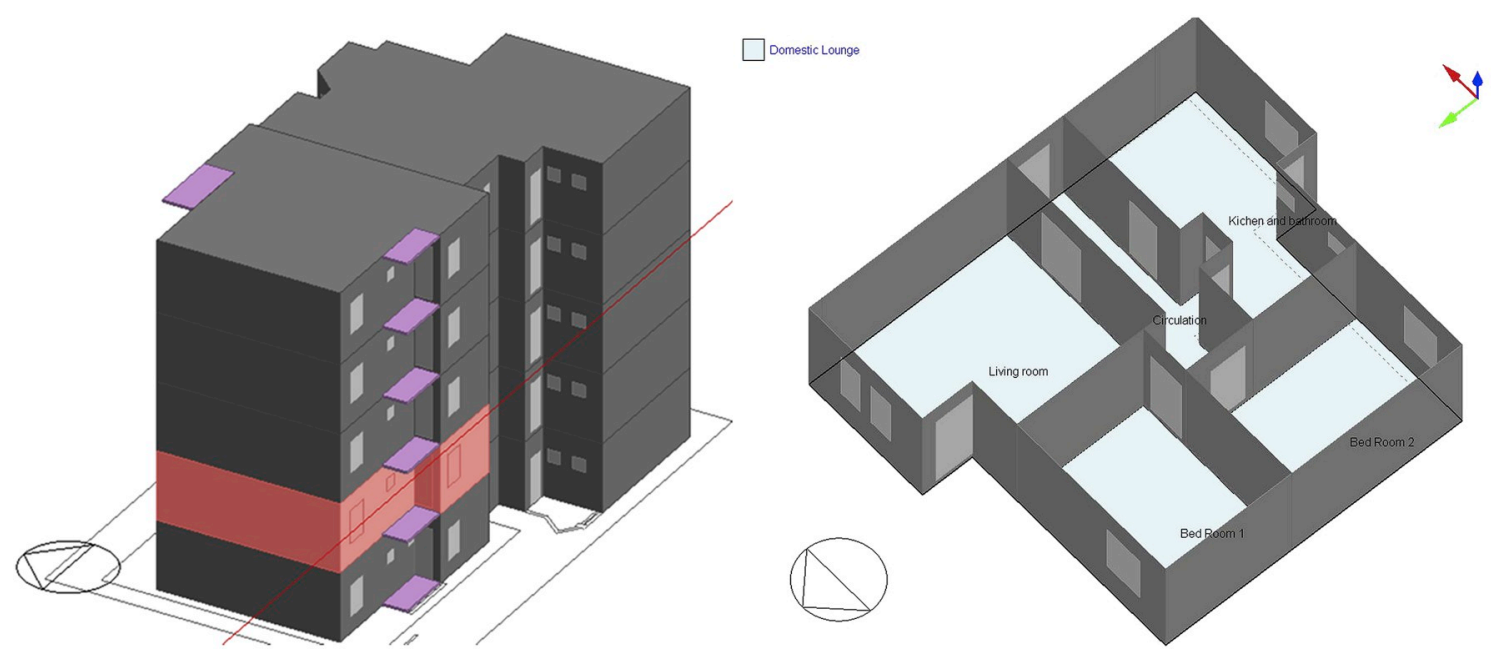

Fig. 4. Simulated building model developed using DesignBuilder (EnergyPlus).

category has two subcategories: winter and summer indoor temperature and electricity and gas consumption. A manual calibration was used and the initial model (reference case) went through several trial-anderror modifications. The airtightness values, schedules (occupancy, lighting, heating, cooling, and DHW), and setpoint temperature values were modified during the calibration. The MBE and CV (RMSE) values were calculated after each simulation run and compared with the accuracy thresholds of ASHRAE Guideline 14. Table 3 and Figure A in the appendix A summarize the final model input. The results of the validation of the simulation model calibration are described in Section 4.2.

\subsection{Calculation and comparison of energy loads}

After validating the building performance simulation model, the thermal comfort and annual energy consumption of the reference case were calculated. The annual energy consumption and discomfort hours of the eight selected locations were simulated. A statistical method was used to compare the results of the simulation and bioclimatic potential. The results of the simulation and the comparison with the bioclimatic potential analysis are described in Section 4.3.

\section{Results}

\subsection{Bioclimatic potential of the eight selected locations}

The monthly minimum and maximum adaptive comfort temperature ranges for the selected eight locations were calculated using the ASHRAE adaptive model and Eqs (1) and (2). The weather data used in this calculation are the averages of 15 years (2003-2017) for each location. Table 4 shows that each city has a monthly upper and lower limit. Based on the identification of the monthly adaptive comfort limit thresholds indicated in Table 4, we selected the highest and lowest comfort temperatures of all months for each location to obtain the annual adaptive comfort temperature range.

The annual bioclimatic potential of the three major design strategies was calculated (see Table 5). The percentage of each bioclimatic strategy's potential is listed in Table 5. The psychrometric charts were plotted using the hourly weather data for each location, as shown in

Table 3

Simulation model parameter input.

\begin{tabular}{|c|c|c|}
\hline & Model input measures & Value \\
\hline \multirow[t]{7}{*}{ Envelope } & External wall (W/m² K) & 1.118 [39] \\
\hline & External wall surface absorptance, CCF & 0.6 \\
\hline & Internal floor $\left(\mathrm{W} / \mathrm{m}^{2} \mathrm{~K}\right)$ & 1.985 \\
\hline & Air tightness (Vol/h) & 3 \\
\hline & WWR (\%) & $11.47^{\circ} \mathrm{N}, 12.78^{\circ} \mathrm{S}$ \\
\hline & Opening $\left(\mathrm{W} / \mathrm{m}^{2} \mathrm{~K}\right)$ & 5.778 \\
\hline & Solar Heat Gain Coefficient (SHGC) & 0.81 \\
\hline \multirow[t]{2}{*}{ Occupancy } & Density (people $/ \mathrm{m}^{2}$ ) & 0.0844 \\
\hline & Schedules & see Fig. A1(a) \\
\hline \multirow[t]{2}{*}{ Lighting } & Installation power density $\left(\mathrm{W} / \mathrm{m}^{2}\right)$ & 15 (to achieve 300 Lux) \\
\hline & Schedules & see Fig. A1(b) \\
\hline \multirow[t]{3}{*}{ Ventilation and air conditioning } & Outside air (1/s per person) & 10 \\
\hline & Temperature setpoint $\left({ }^{\circ} \mathrm{C}\right)$ & Heating $22^{\circ} \mathrm{C}$, Cooling $28^{\circ} \mathrm{C}[39,49]$ \\
\hline & COP/EER & $1.8 / 1.8$ \\
\hline \multirow[t]{3}{*}{ DHW } & Winter period (December-March) $\left(1 / \mathrm{m}^{2} /\right.$ day $)$ & 3.15 \\
\hline & Midseason period (April and May, October and November) (1/m2/day) & 1.89 \\
\hline & Schedules & see Fig. A1(c) \\
\hline Plug loads & Average installation power density $\left(\mathrm{W} / \mathrm{m}^{2}\right)$ & 10 \\
\hline
\end{tabular}


Table 4

Indoor adaptive comfort temperatures $\left({ }^{\circ} \mathrm{C}\right)$ for the eight selected locations in 2016.

\begin{tabular}{|c|c|c|c|c|c|c|c|c|c|c|c|c|c|c|c|}
\hline No & Name of City & 90\% Acceptability Range & Jan & Feb & Mar & Apr & May & Jun & Jul & Aug & Sep & Oct & Nov & Dec & Annual \\
\hline \multirow[t]{2}{*}{1} & Algiers & $\operatorname{Max}\left({ }^{\circ} \mathrm{C}\right)$ & 23.6 & 23.4 & 24.3 & 15.2 & 26.2 & 27.3 & 28.3 & 28.4 & 27.6 & 26.7 & 24.8 & 24 & 28.4 \\
\hline & & $\operatorname{Min}\left({ }^{\circ} \mathrm{C}\right)$ & 18.6 & 18.4 & 19.3 & 20.2 & 21.2 & 22.3 & 23.3 & 23.4 & 22.6 & 21.7 & 19.8 & 19 & 18.4 \\
\hline \multirow[t]{2}{*}{2} & Guelma & $\operatorname{Max}\left({ }^{\circ} \mathrm{C}\right)$ & 22.9 & 22.9 & 23.9 & 24.6 & 26.1 & 27.1 & 28.7 & 28.1 & 27 & 26.4 & 24.6 & 23.4 & 28.7 \\
\hline & & $\operatorname{Min}\left({ }^{\circ} \mathrm{C}\right)$ & 18.4 & 18.4 & 18.9 & 19.6 & 21.1 & 22.1 & 23.7 & 23.1 & 22 & 21.4 & 19.6 & 18.4 & 18.4 \\
\hline \multirow[t]{2}{*}{3} & Chlef & $\operatorname{Max}\left({ }^{\circ} \mathrm{C}\right)$ & 23.6 & 23.5 & 24.8 & 25.6 & 26.8 & 28.9 & 29.5 & 29.4 & 28.2 & 27.3 & 25.1 & 24.1 & 29.5 \\
\hline & & $\operatorname{Min}\left({ }^{\circ} \mathrm{C}\right)$ & 18.6 & 18.5 & 19.8 & 20.6 & 21.8 & 23.9 & 24.5 & 24.4 & 23.2 & 22.3 & 20.1 & 19.1 & 18.5 \\
\hline \multirow[t]{2}{*}{4} & Setif & $\operatorname{Max}\left({ }^{\circ} \mathrm{C}\right)$ & 21.7 & 21.7 & 23.1 & 24.2 & 25.3 & 27.3 & 28.4 & 28.2 & 26.6 & 25.4 & 23.5 & 22 & 28.4 \\
\hline & & $\operatorname{Min}\left({ }^{\circ} \mathrm{C}\right)$ & 18.4 & 18.4 & 18.4 & 19.2 & 20.3 & 22.3 & 23.4 & 23.2 & 21.6 & 20.4 & 18.5 & 17 & 18.4 \\
\hline \multirow[t]{2}{*}{5} & Biskra & $\operatorname{Max}\left({ }^{\circ} \mathrm{C}\right)$ & 24 & 24.3 & 25.7 & 27 & 28.6 & 30.1 & 30.6 & 30.6 & 29.1 & 27.7 & 25.47 & 24.2 & 30.6 \\
\hline & & $\operatorname{Min}\left({ }^{\circ} \mathrm{C}\right)$ & 19 & 19.3 & 20.7 & 22 & 23.6 & 25.1 & 26.1 & 25.9 & 24.1 & 22.7 & 20.4 & 19.2 & 19 \\
\hline \multirow[t]{2}{*}{6} & Bechar & $\operatorname{Max}\left({ }^{\circ} \mathrm{C}\right)$ & 23.5 & 24.2 & 25.6 & 27.3 & 28.2 & 29.8 & 30.6 & 30.9 & 29.2 & 27.5 & 24.7 & 23.3 & 30.6 \\
\hline & & $\operatorname{Min}\left({ }^{\circ} \mathrm{C}\right)$ & 18.5 & 19.2 & 20.6 & 22.3 & 23.2 & 24.8 & 26.2 & 25.9 & 24.2 & 22.5 & 19.7 & 18.4 & 18.4 \\
\hline \multirow[t]{2}{*}{7} & Adrar & $\operatorname{Max}\left({ }^{\circ} \mathrm{C}\right)$ & 24.3 & 25.7 & 26.9 & 28.2 & 30.1 & 30.6 & 30.6 & 30.6 & 30.5 & 28.8 & 26.1 & 24.5 & 30.6 \\
\hline & & $\operatorname{Min}\left({ }^{\circ} \mathrm{C}\right)$ & 19.3 & 20.7 & 21.9 & 23.2 & 25.1 & 26.3 & 27.2 & 26.9 & 25.5 & 23.8 & 21.1 & 19.5 & 19.3 \\
\hline \multirow[t]{2}{*}{8} & Tamanrasset (in Guezzam) & $\operatorname{Max}\left({ }^{\circ} \mathrm{C}\right)$ & 26 & 27.1 & 29 & 30.1 & 30.6 & 30.6 & 30.6 & 30.6 & 30.6 & 29.6 & 28.4 & 27.2 & 30.6 \\
\hline & & $\operatorname{Min}\left({ }^{\circ} \mathrm{C}\right)$ & 21 & 22.1 & 24 & 25.1 & 26.6 & 26.8 & 26.5 & 26.2 & 26.1 & 24.6 & 23.4 & 22.2 & 21 \\
\hline
\end{tabular}

Fig. 5.

\subsubsection{Annual thermal comfort potential}

The annual thermal comfort potential (\%) was calculated for the different locations, as shown in Fig. 6. It represents the percentage of comfortable time (h) during the year without the use of any bioclimatic strategies. Fig. 6 shows that the weather in Chlef is characterized by the highest number of hours within the comfort limits (28\%). This location has a higher comfort period compared with the other locations in Algeria. In contrast, the annual comfort potential of Setif and Tamanrasset (within the Tamanrasset Province) is $\sim 18.5 \%$. These locations have the lowest number of comfort hours throughout the year.

\subsubsection{Annual natural ventilation potential}

The annual natural ventilation potential (\%) was calculated for the different locations shown in Fig. 7a. The natural ventilation strategy allows to extend the upper comfort threshold to a maximum of $3{ }^{\circ} \mathrm{C}$ according to ASHRAE 55 [50]. As shown in Fig. 7a, the highest potential to increase the comfort hours by natural ventilation was observed in Chlef and Algiers $(\sim 19 \%)$. In contrast, Setif has the lowest value (11.6\%); natural ventilation can be considered as an effective passive strategy.

\subsubsection{Annual direct evaporative cooling potential}

The annual evaporative cooling potential (\%) for the different locations was calculated, as shown in Fig. $7 \mathrm{~b}$. It represents the percentage of time during the year during which the comfort limit is extended above the upper limits of comfort by using direct evaporative cooling. Evaporative cooling can extend the comfort period by $\sim 47.5 \%$ in Tamanrasset (in Guezzam). This value shows that evaporative cooling is very effective in the Tamanrasset Province. In contrast, evaporative cooling is the least effective strategy in Algiers (3\%).

\subsubsection{Annual passive solar heating potential}

The annual passive solar heating potential (\%) for the different locations is shown in Fig. 7c. It represents the percentage of time during the year during which the comfort is extended below the lower comfort threshold through direct solar radiation. Passive solar heating extends the comfort period by $\sim 14 \%$ in Chlef, which has the highest potential compared with the other locations. The lowest passive solar heating potential is obtained in Tamanrasset (1\%).

\subsection{Validation of the simulation model calibration}

The MBE and CV(RMSE) were used for different comparisons between measured and simulated data. Table 6 outlines the MBE and CV (RMSE) calibration results. The model was validated using Table 6.

Fig. 8 shows the comparison between the measured and simulated indoor temperatures for the monitored periods. In the winter period, the MBE is $-2 \%$ and the CV(RMSE) is $5.1 \%$, while the admitted limit is $\pm 10 \%$ and $\pm 30 \%$, respectively. In the summer period, the MBE is $-1.5 \%$ and the CV(RMSE) is $4.9 \%$, while the admitted limit is $\pm 10 \%$ and $\pm 30 \%$, respectively. The model MBE and CV(RMSE) values for the hourly data are within ASHRAE-recommended hourly values. The

Table 5

Annual potential (\%) of thermal comfort and passive heating/cooling strategies for the eight selected locations.

\begin{tabular}{|c|c|c|c|c|c|c|}
\hline No. & Name of City & Comfort (\%) & $\begin{array}{l}\text { Natural Ventilation } \\
(\%)\end{array}$ & $\begin{array}{l}\text { Direct Evaporative Cooling } \\
(\%)\end{array}$ & $\begin{array}{l}\text { Passive Solar Heating } \\
(\%)\end{array}$ & $\begin{array}{l}\text { Natural Ventilation }+ \text { Direct Evaporative } \\
\text { Cooling (\%) }\end{array}$ \\
\hline 1 & Algiers & 22.1 & 18.9 & 2.9 & 13.1 & 21.9 \\
\hline 2 & Guelma & 18.6 & 13.7 & 4 & 11.9 & 17.8 \\
\hline 3 & Chlef & 27.9 & 18.9 & 10.5 & 10.3 & 29.4 \\
\hline 4 & Setif & 18.4 & 11.5 & 9.9 & 13.9 & 21.5 \\
\hline 5 & Biskra & 26.4 & 17.4 & 21.5 & 9.3 & 39 \\
\hline 6 & Bechar & 23.8 & 16.3 & 30.3 & 10.8 & 46.7 \\
\hline 7 & Adrar & 23.8 & 15.1 & 38.7 & 4.6 & 53.9 \\
\hline 8 & $\begin{array}{l}\text { Tamanrasset (in } \\
\text { Guezzam) }\end{array}$ & 18.5 & 12.5 & 47.5 & 0.8 & 60 \\
\hline
\end{tabular}


Algiers

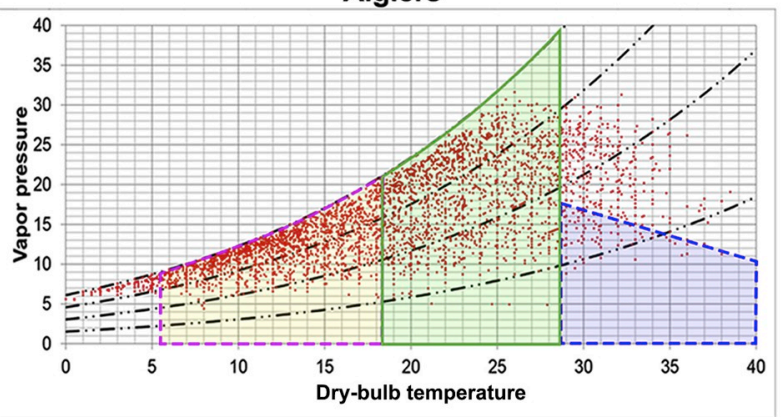

(a)

Chlef

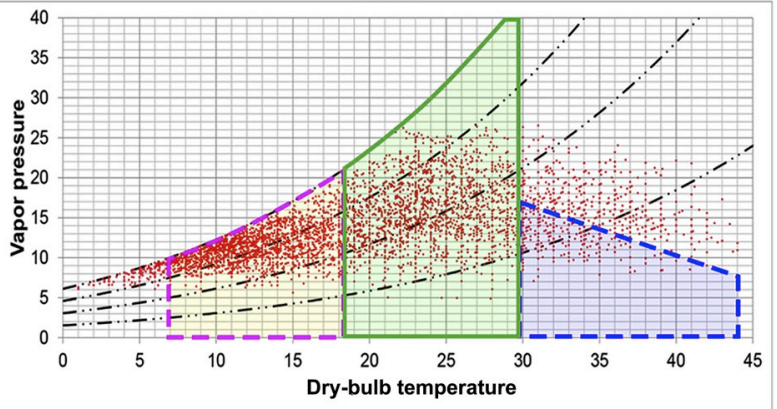

(c)

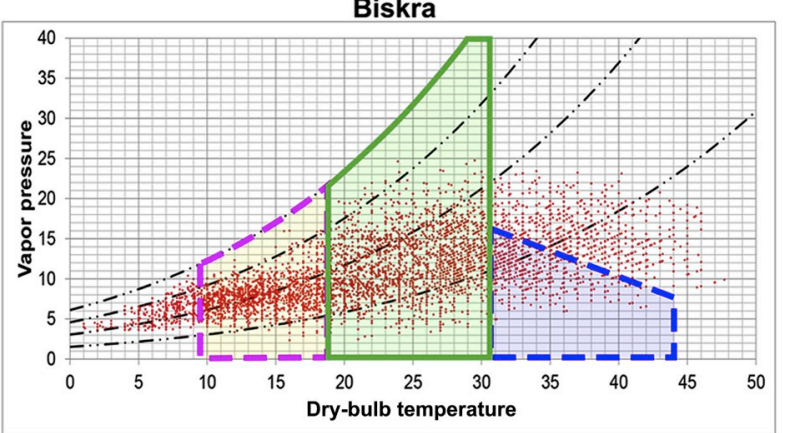

(e)

Adrar

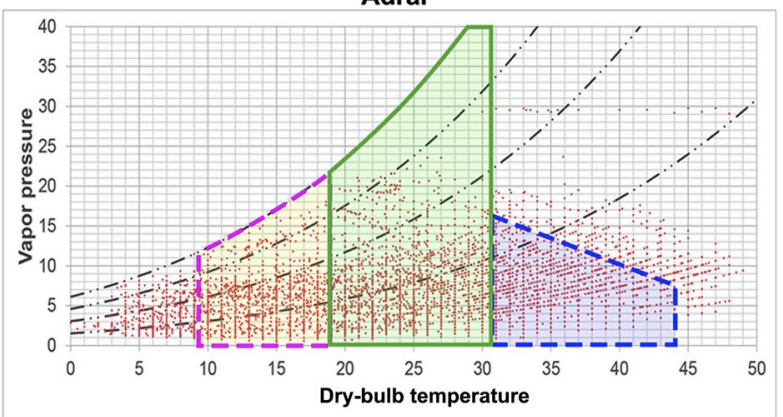

(g)

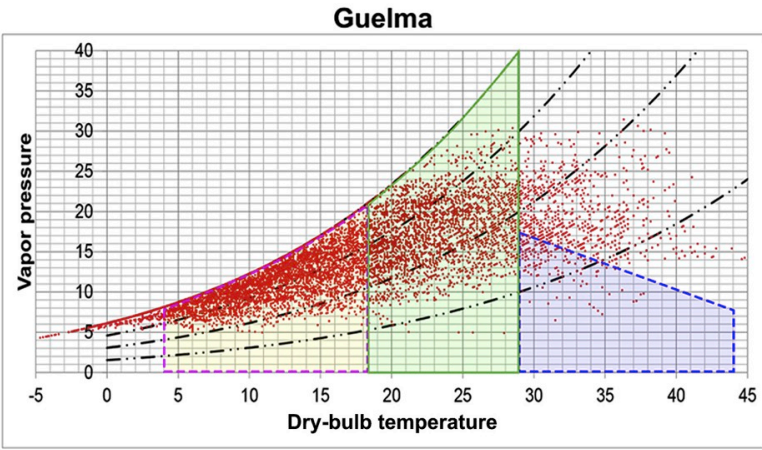

(b)

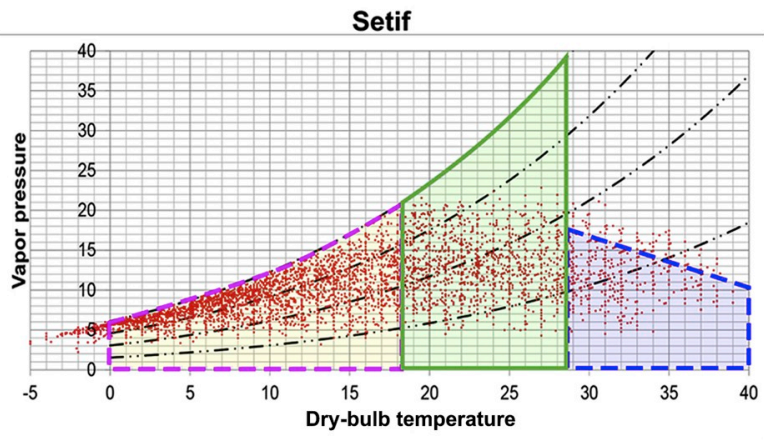

(d)

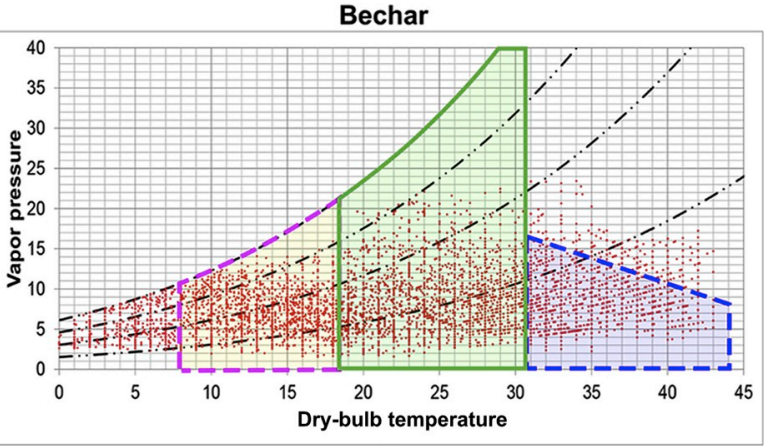

(f)

Tamanrasset (in Guezem)

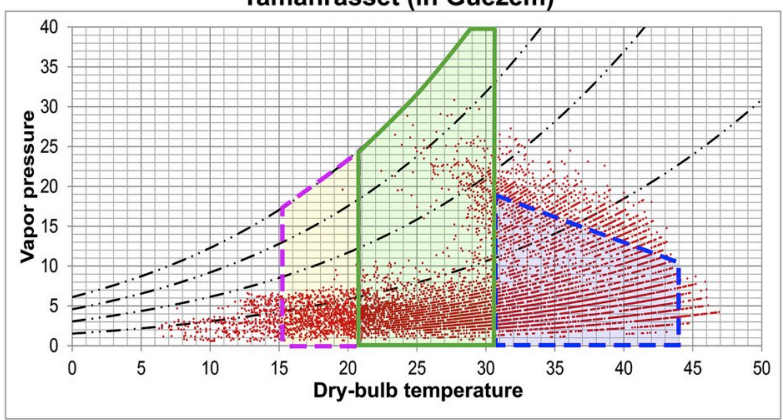

(h)

Passive solar heating boundary $\square$ Adaptive comfort ventilation boundary

Fig. 5. Bioclimatic chart with hourly weather data for (a) Algiers, (b) Guelma, (c) Chlef, (d) Setif, (e) Biskra, (f) Bechar, (g) Adrar, and (h) Tamanrasset. 


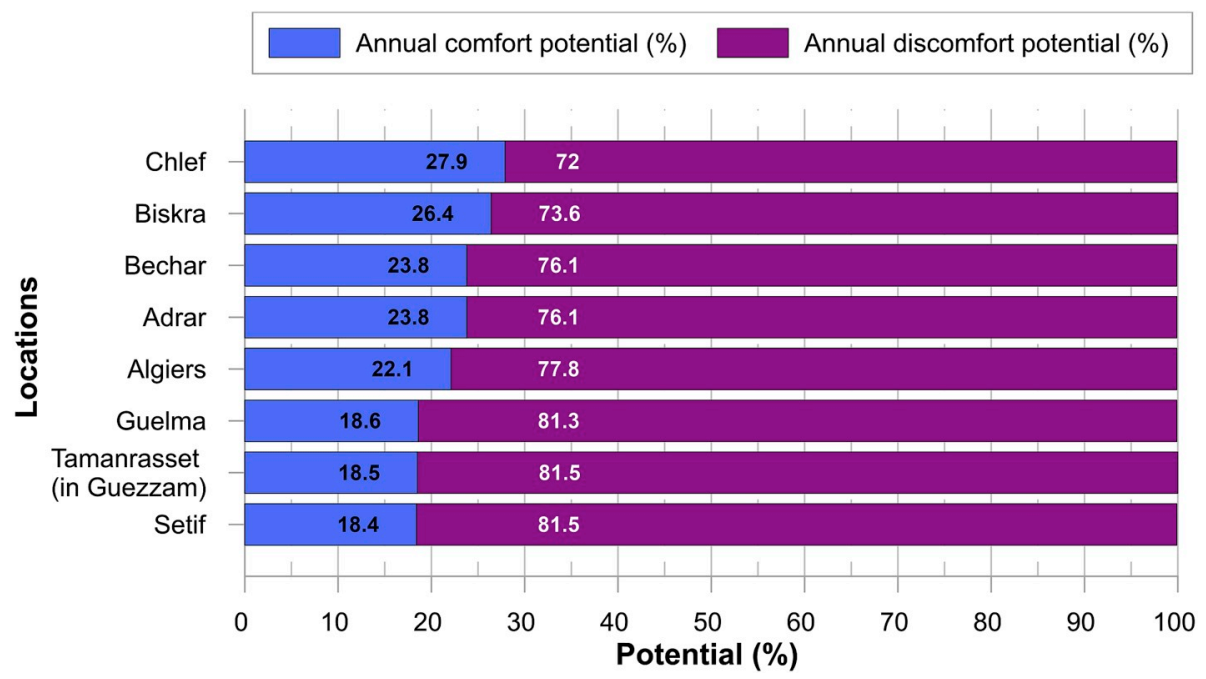

Fig. 6. Annual thermal comfort potential (\%) for the eight selected locations.

simulation model was calibrated using hourly data.

Fig. 9 shows the comparison between the measured and simulated energy consumptions during the monitored periods. For the electricity consumption, the MBE is $-0.6 \%$ and the CV(RMSE) is $7.8 \%$, while the admitted limit is $\pm 5 \%$ and $\pm 15 \%$, respectively. For the gas consumption, the MBE is $0.4 \%$ and the CV(RMSE) is $6.6 \%$, while the admitted limit is $\pm 5 \%$ and $\pm 15 \%$, respectively. The model MBE and CV (RMSE) values for the monthly data are within ASHRAE-recommended hourly values. The simulation model was calibrated using monthly data, which validate it.

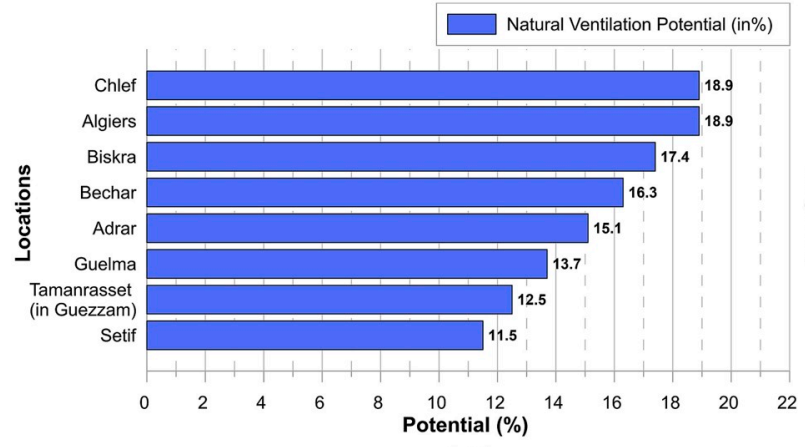

(a)

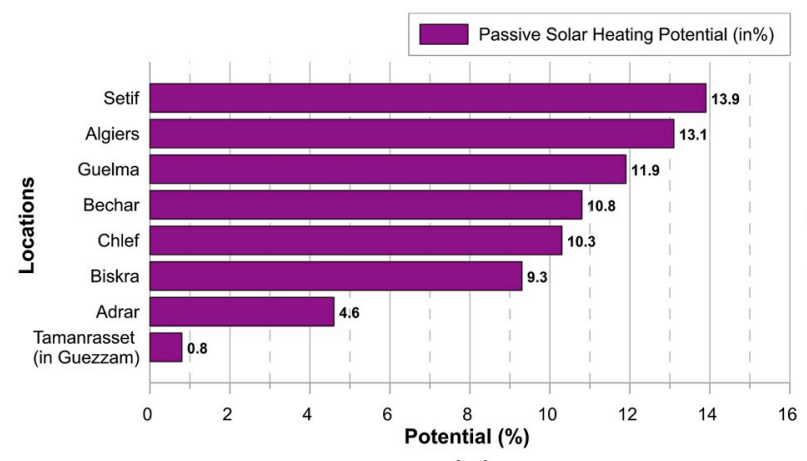

(c)

\subsection{Energy loads for the eight selected locations}

\subsubsection{Annual cumulative comfort potential and simulated discomfort hours}

The annual cumulative comfort potential represents the percentage of time during the year during which comfort is achieved by using passive strategies (Natural Ventilation (NV), Direct Evaporative Cooling (DEC), and Passive Solar Heating (PSH)). The annual simulated discomfort hours indicate the percentage of time during the year during which passive or active strategies are necessary to achieve comfort. Fig. 10 shows the comparison between the annual cumulative comfort

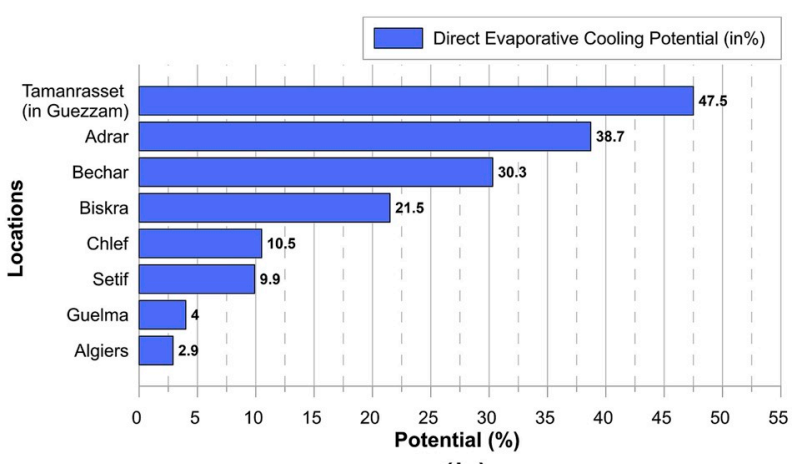

(b)

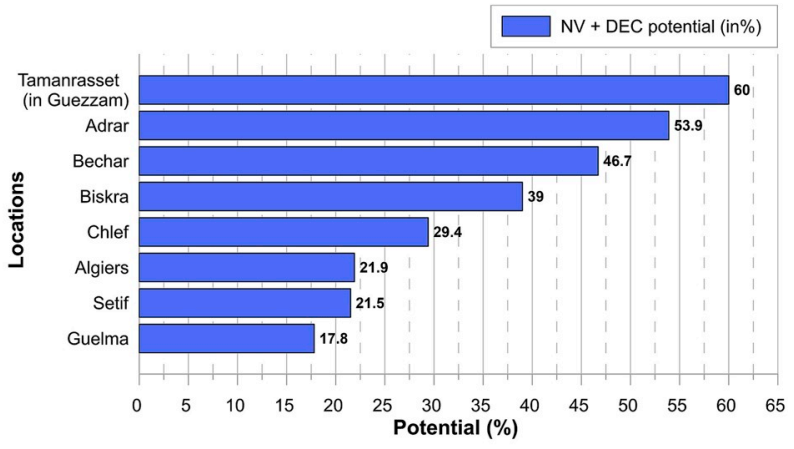

(d)

Fig. 7. Annual passive design potential (\%) for the eight selected locations. (a) natural ventilation, (b) direct evaporative cooling, (c) passive solar heating, and (d) natural ventilation and direct evaporative cooling. 
Table 6

Summary of the validation of the calibration criteria of the simulation model.

\begin{tabular}{|c|c|c|c|c|}
\hline Validation criteria & Winter indoor air temperature & Summer indoor air temperature & Monthly electricity consumption & Monthly gas consumption \\
\hline MBE (\%) & -2 & -1.5 & -0.6 & 0.4 \\
\hline CV (RMSE) (\%) & 5.1 & 4.9 & 7.8 & 6.6 \\
\hline
\end{tabular}

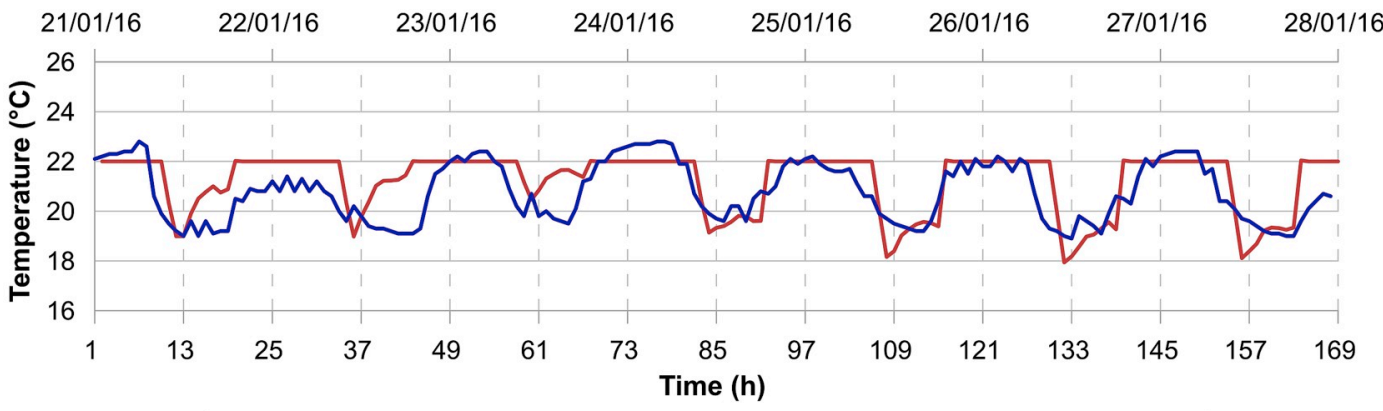

Simulated indoor air temperature $\left({ }^{\circ} \mathrm{C}\right) \quad$ Monitored indoor air temperature $\left({ }^{\circ} \mathrm{C}\right)$

(a)

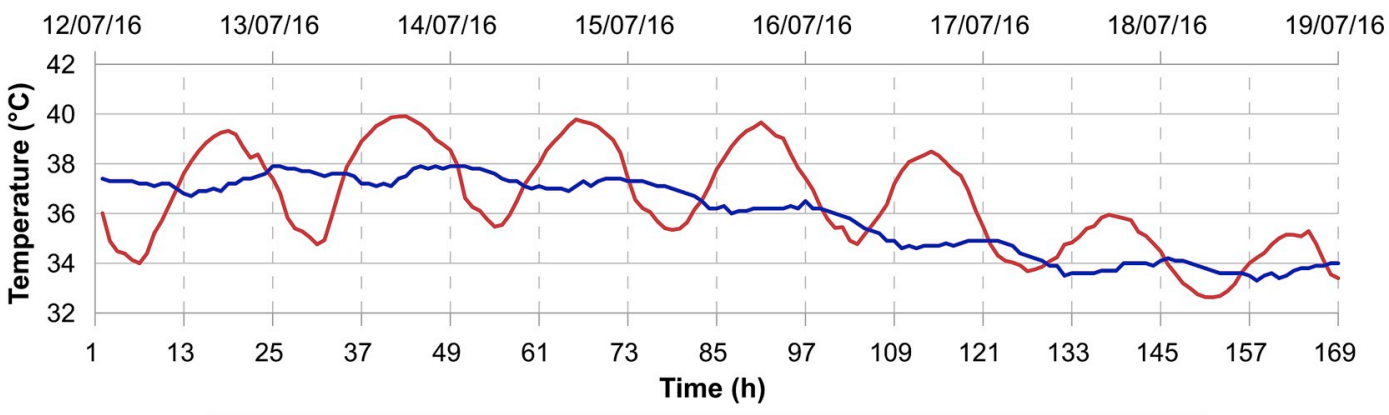

Simulated indoor air temperature $\left({ }^{\circ} \mathrm{C}\right) \quad$ Monitored indoor air temperature $\left({ }^{\circ} \mathrm{C}\right)$

(b)

Fig. 8. Comparison between measured and simulated indoor temperatures during the monitored period. (a) January 21-27, 2016; (b) July 12-18, 2016.

potential (estimated potential) and annual simulated discomfort hours for the eight selected locations.

The combination of the bioclimatic strategies in Adrar has a comfort potential of $82 \%$. This is the highest value compared with the other locations. However, the simulation result lowers the potential comfort estimation coverage to $\sim 75 \%$. In fact, the simulation results indicate that Adrard, Bechar, Tamanrasset, and Biskra have a potential of $75 \%$ to passively achieve thermal comfort. On the other hand, nearly $48.5 \%$ of the total annual hours are potentially comfortable if all passive strategies would be combined in Guelma. This is the lowest value compared with the other locations. However, the simulation result increases the potential comfort estimation coverage to $\sim 63 \%$. The comfort potential calculation and simulation analysis for Chlef and Algiers yield almost identical results, as shown in Fig. 11.

To determine the correlation between the psychrometric-based and simulation-based analysis results, Fig. 12 shows the results of the linear regression analysis between the annual cumulative comfort potential and annual simulated discomfort hours. The regression analysis between the annual cumulative comfort potential and annual simulated discomfort hours indicates a strong correlation, with a Pearson correlation coefficient $(\mathrm{R})$ of 0.8 and regression coefficient $\left(\mathrm{R}^{2}\right)$ of 0.6 (Table 7).

4.3.2. Annual passive cooling potential and annual cooling load

The annual passive cooling potential represents the addition of the annual natural ventilation and annual evaporative cooling potential. This value indicates the period of time during which cooling is required and thus the cooling energy consumption. Fig. 13 shows the comparison between the annual passive cooling potential (estimated cooling potential based on the psychrometric chart) and annual cooling load (simulated cooling load) for the eight selected locations. Tamanrasset has the highest annual passive cooling potential $(60 \%)$ as well as the highest annual cooling energy consumption $\left(163.9 \mathrm{kWh} / \mathrm{m}^{2}\right)$ compared with the other locations. Guelma, Setif, and Algiers have the lowest passive cooling potentials (between $17.8 \%$ and $21.9 \%$ ) as well as the lowest cooling loads $\left(6.1 \mathrm{kWh} / \mathrm{m}^{2}\right.$ for Setif, $9.9 \mathrm{kWh} / \mathrm{m}^{2}$ for Algiers, and $13.3 \mathrm{kWh} / \mathrm{m}^{2}$ for Guelma). Fig. 14 shows the results of the linear regression analysis between the annual passive cooling potential and annual cooling load for the eight selected locations. The regression analysis between the annual cooling potential and annual cooling load indicates a strong correlation, with a Pearson correlation coefficient $(\mathrm{R})$ of 0.96 and regression coefficient $\left(R^{2}\right)$ of 0.9 (Table 7).

\subsubsection{Annual passive solar heating potential and annual heating load}

The passive solar heating potential indicates the period of time during which heating is required and thus the heating energy consumption. Fig. 15 shows the comparison between the annual passive heating potential (estimated heating potential) and annual heating load (simulated heating load) for the eight selected locations. The passive solar heating potential of all locations is low and does not exceed $14 \%$. 


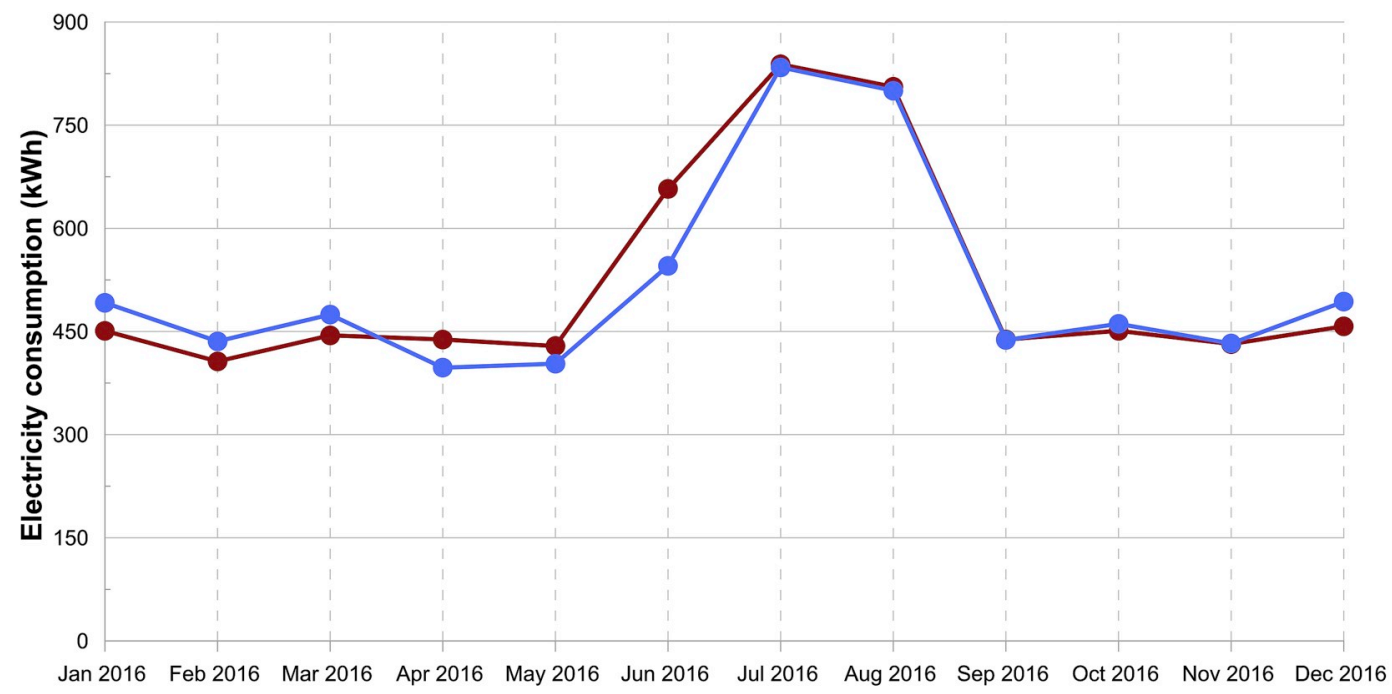

Simulated electricity consumption (kWh) Monitored electricity consumption (kWh)

(a)

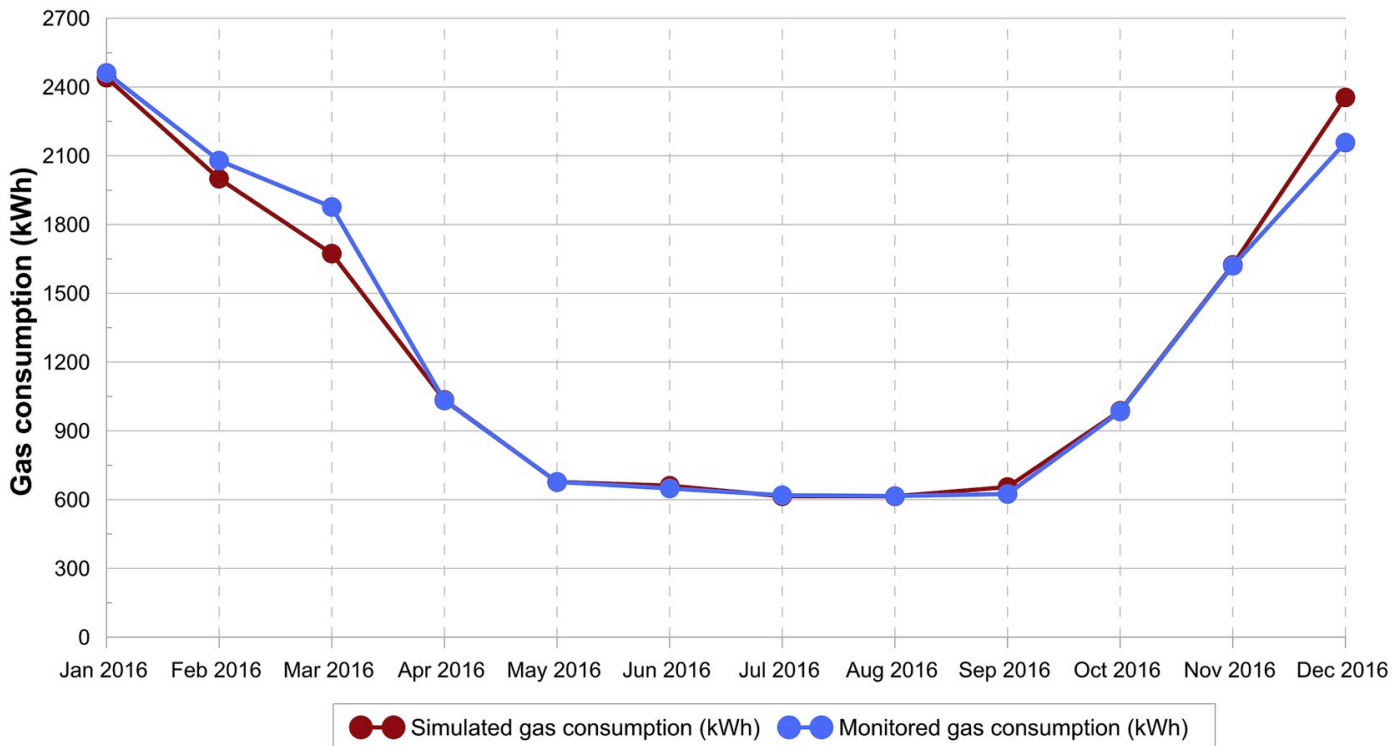

(b)

Fig. 9. Monthly comparisons of the monitored and simulated energy and consumptions for 2016. (a) electric consumption, (b) gas consumption.

Setif has the highest annual passive heating potential (13.9\%) as well as the highest annual heating energy consumption $\left(180.8 \mathrm{kWh} / \mathrm{m}^{2}\right)$ compared with the other locations. Tamanrasset has the lowest passive heating potential $(0.8 \%)$ as well as the lowest heating load $(5.1 \mathrm{kWh} /$ $\mathrm{m}^{2}$ ). Fig. 16 shows the results of the linear regression analysis between the annual passive heating potential and annual heating load for the eight selected locations. The regression analysis between the annual heating potential and annual heating load indicates a strong correlation, with a Pearson correlation coefficient $(\mathrm{R})$ of 0.88 and regression coefficient $\left(\mathrm{R}^{2}\right)$ of 0.7 (Table 7).

\section{Discussion}

\subsection{Summary of the main findings}

In this study, we performed a climatic analysis of eight Algerian cities to assess the effectiveness of bioclimatic design strategies. We applied a mixed approach that combines psychometric chart analysis and building performance simulation analysis. By using recent and high-quality weather datasets, we quantified the effectiveness of bioclimatic design strategies based on an accurate and modern approach using a recent adaptive comfort model (ASHARE 55-2017). Our study findings indicate that psychrometric chart-based bioclimatic potential analysis for all investigated locations does not correspond with the simulation-based energy and comfort analysis (see Table 8). For example, the estimation of the discomfort hours in Algiers is almost identical, (57\% and 58\%), when calculated using both approaches. This result agrees with the results of Ali-Toudert et al. [37] who evaluated the A and D climate zones. The cumulative comfort potential analysis results (using psychrometric charts and building performance simulations) for almost all cities are almost identical, except for Setif and Guelma for which the psychrometric charts indicate a significant underestimation of the discomfort hours compared with the simulation results (see Fig. 10).

To summarize the major simulation-based findings, we list the most important and tangible outcomes of our bioclimatic analysis of the thermal comfort (see Table 8): 


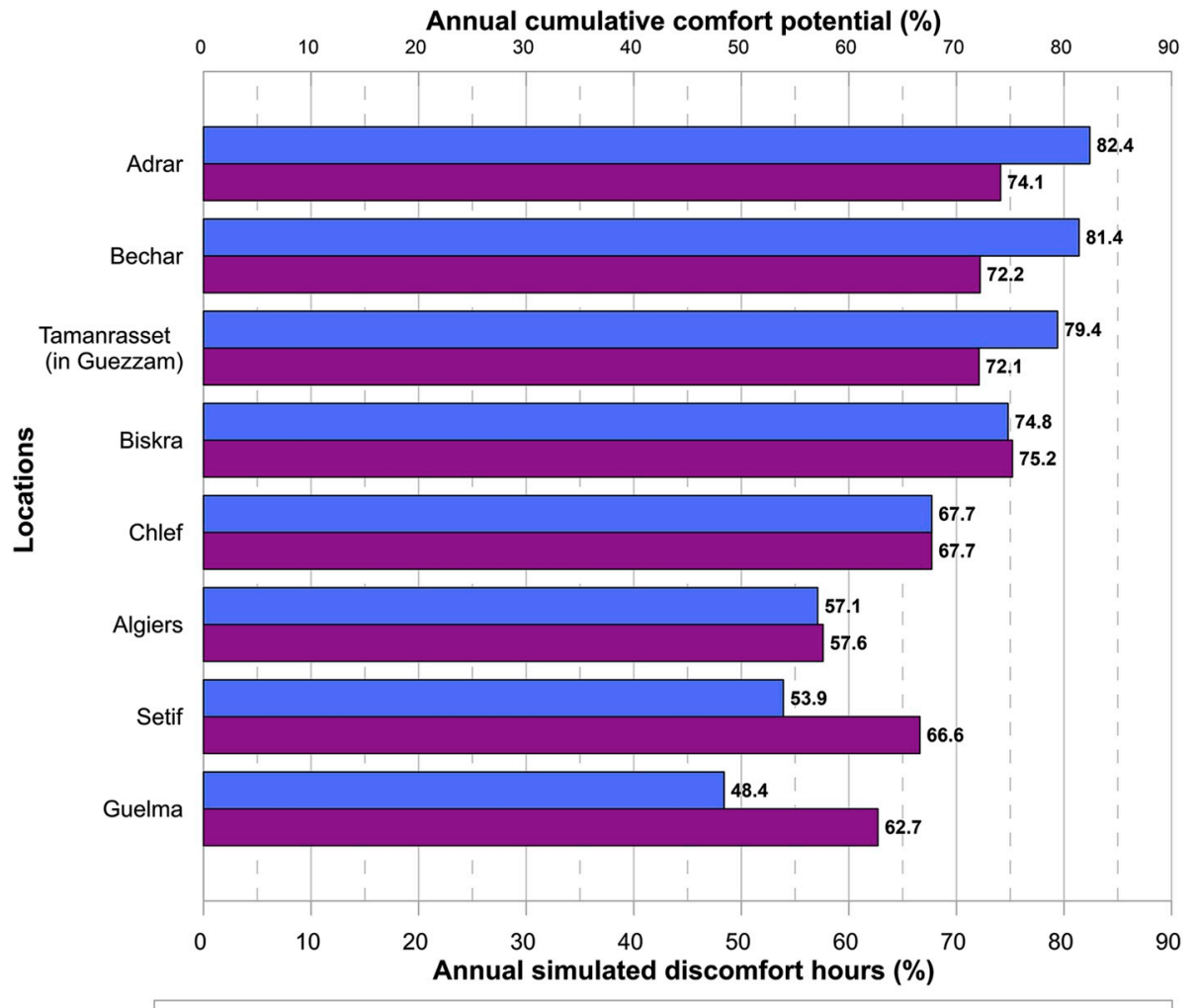

Annual simulated discomfort hours (\%) $\square$ Annual cumulative comfort potential (\%)

Fig. 10. Comparison between the annual cumulative comfort potential (\%) and annual simulated discomfort hours (\%).

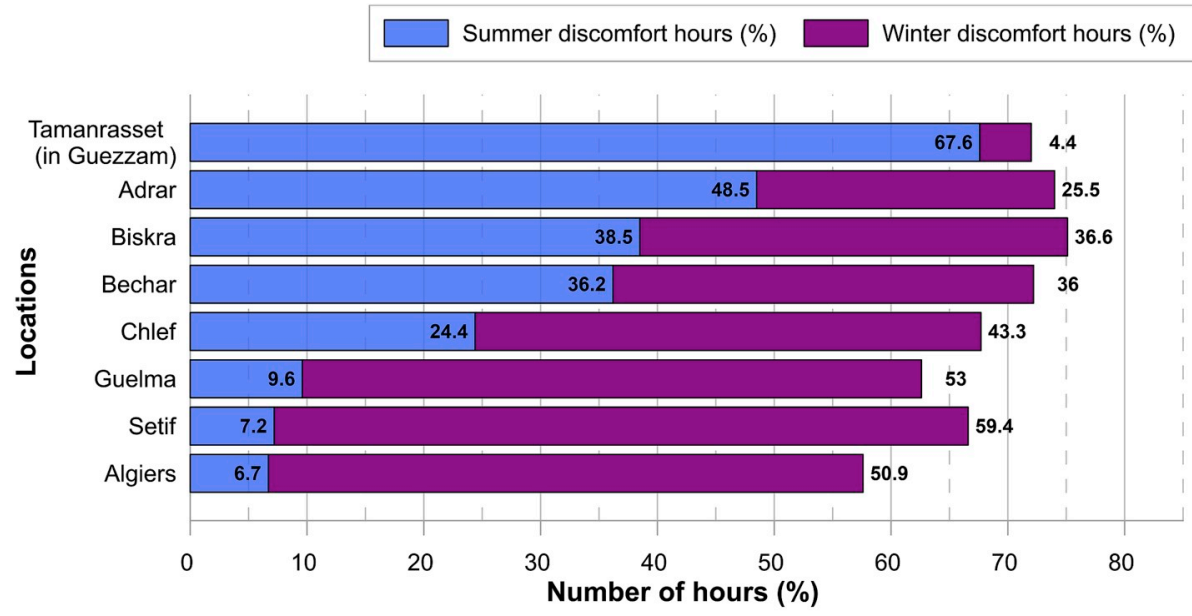

Fig. 11. Percentage of the annual simulated discomfort hours in winter and summer based on the ASHRAE-55 adaptive comfort model (90\% limit).

- Based on our simulation, Guelma, Setif, and Algiers have common summer discomfort hours ranging between $7 \%$ and $10 \%$, while the winter discomfort hours range between $51 \%$ and $60 \%$.

- Chlef, Bechar, Biskra, and Adrar have summer discomfort hours ranging between $25 \%$ and $49 \%$, while the winter discomfort hours range between $26 \%$ and $43 \%$.Surprisingly, Chlef, which is located in the north of Algeria (Zone $\mathrm{B}^{\prime}$ ), has the same discomfort hours percentage as Zone D in the south of Algeria (desert).

- The percentage of summer discomfort hours in Tamanrasset is above $67 \%$, while that of the winter discomfort hours is below $5 \%$. This result can be explained by the solar radiation parameter, which is very high in this zone. It can exceed $7000 \mathrm{Wh} / \mathrm{m}^{2}$, which was confirmed by Yaiche et al. (2014) [40].
Our bioclimatic analysis results regarding the passive cooling potential are listed below:

- The bioclimatic potential analysis overestimates the cooling needs of most locations, except for Adrar and Tamanrasset.

- Regarding the passive cooling, our annual cooling load calculation indicates that Adrar and Tamanrasset are the locations with the highest amounts, with cooling requirements as reported by Ghedamsiet al. (2016) [36]. Tamanrasset is followed by Bechar, Biskra, and Chlef.

- The locations with the least cooling requirements are grouped and include Algiers, Setif, and Guelma because they more easily receive humid winds from the sea (see Fig. 13 and Table 8) [51]. 


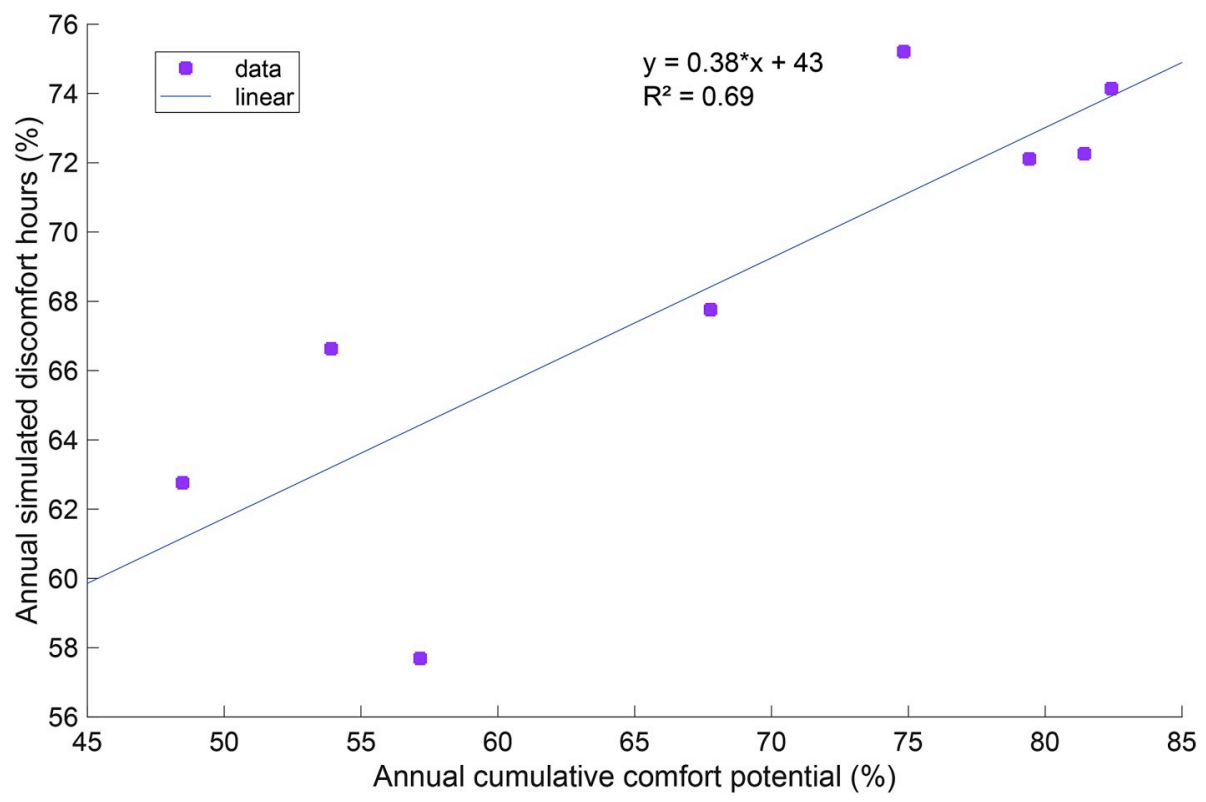

Fig. 12. Linear regression of the annual cumulative comfort potential (\%) and annual simulated discomfort hours (\%).

Table 7

Summary of the validation of the linear regression between the annual bioclimatic potential and annual energy loads.

\begin{tabular}{|c|c|c|}
\hline Validation criteria & R (Pearson correlation coefficient) & $\mathrm{R}^{2}$ (Regression coefficient) \\
\hline Passive cooling potential/cooling load & 0.9 & 0.9 \\
\hline Passive heating potential/heating load & 0.8 & 0.7 \\
\hline Cumulative comfort potential/simulated discomfort hours & 0.8 & 0.6 \\
\hline
\end{tabular}

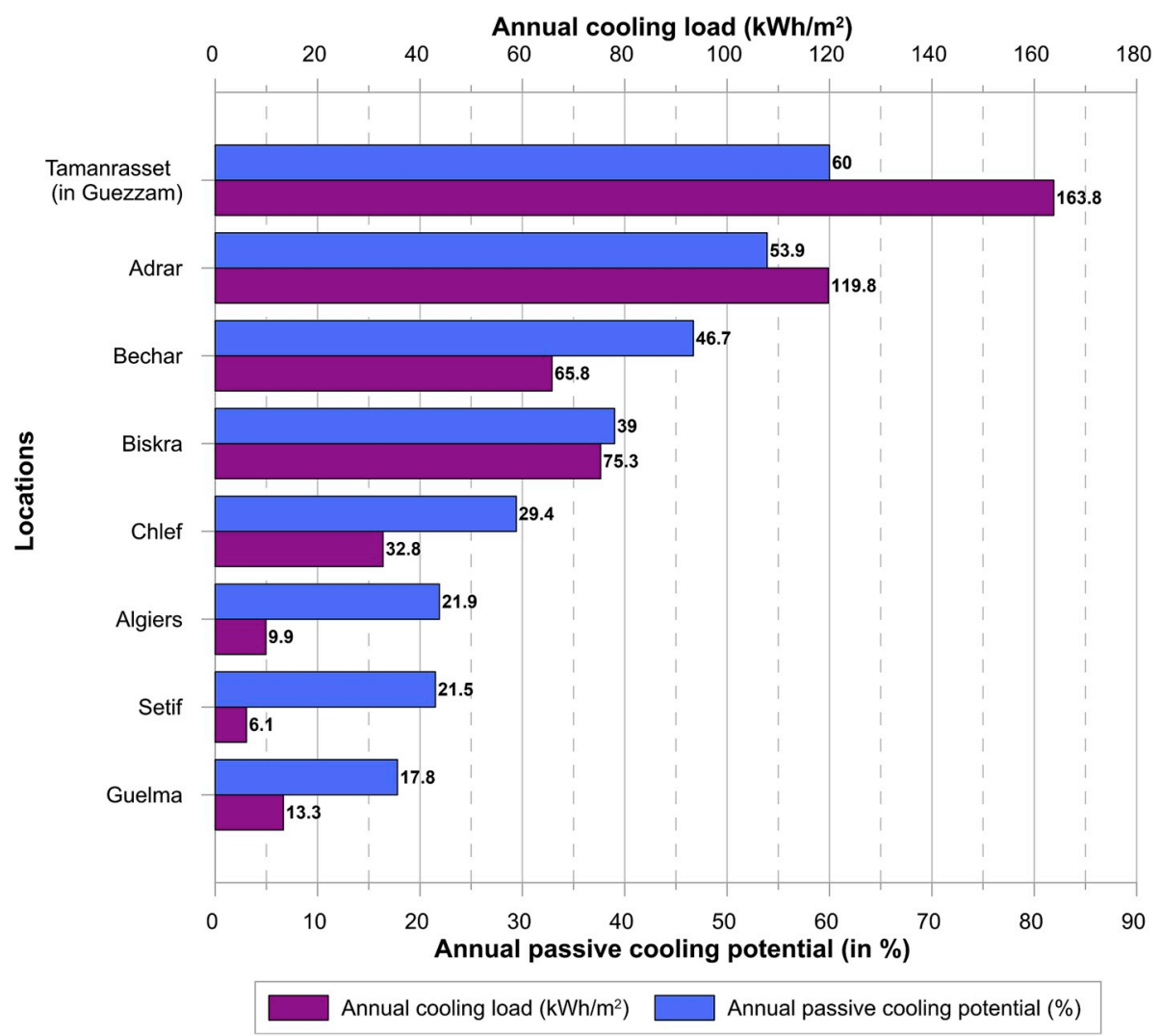

Fig. 13. Comparison between the annual passive cooling potential (\%) and annual cooling load $\left(\mathrm{kWh} / \mathrm{m}^{2}\right)$. 


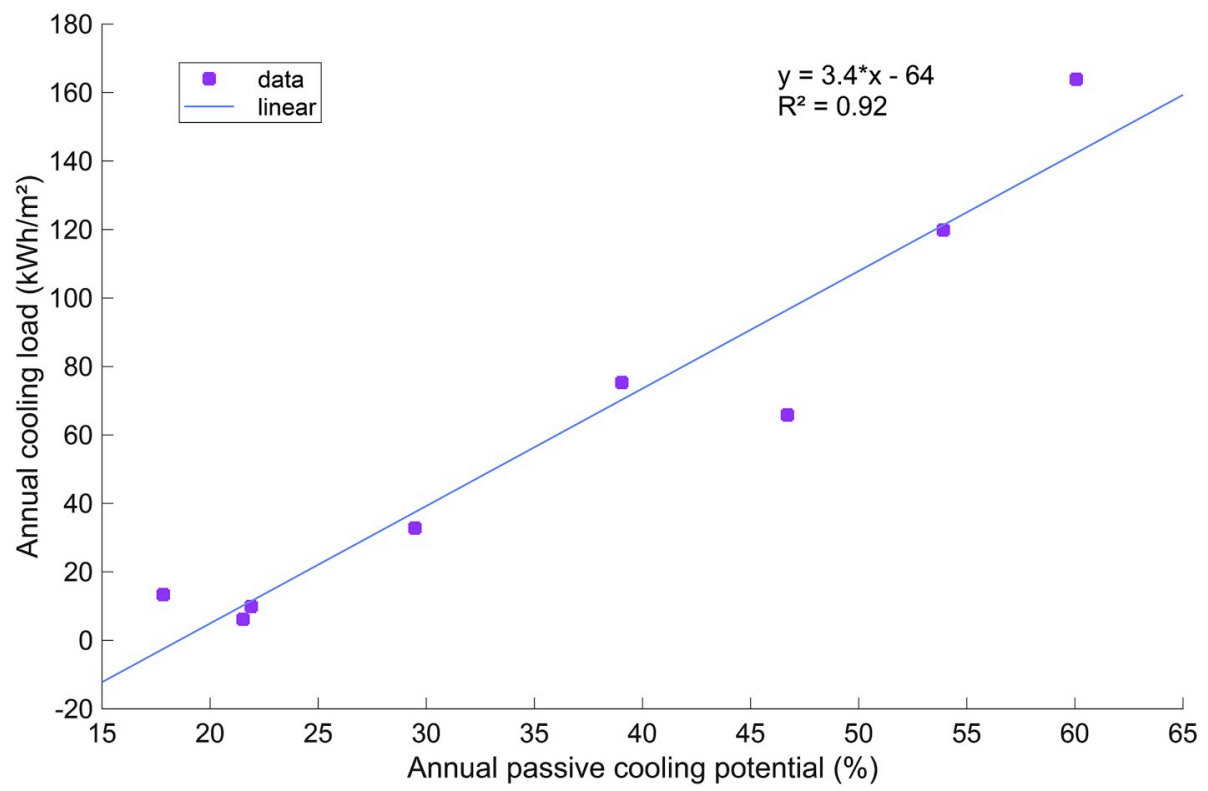

Fig. 14. Linear regression of the annual passive cooling potential (\%) and annual cooling load $\left(\mathrm{kWh} / \mathrm{m}^{2}\right)$.

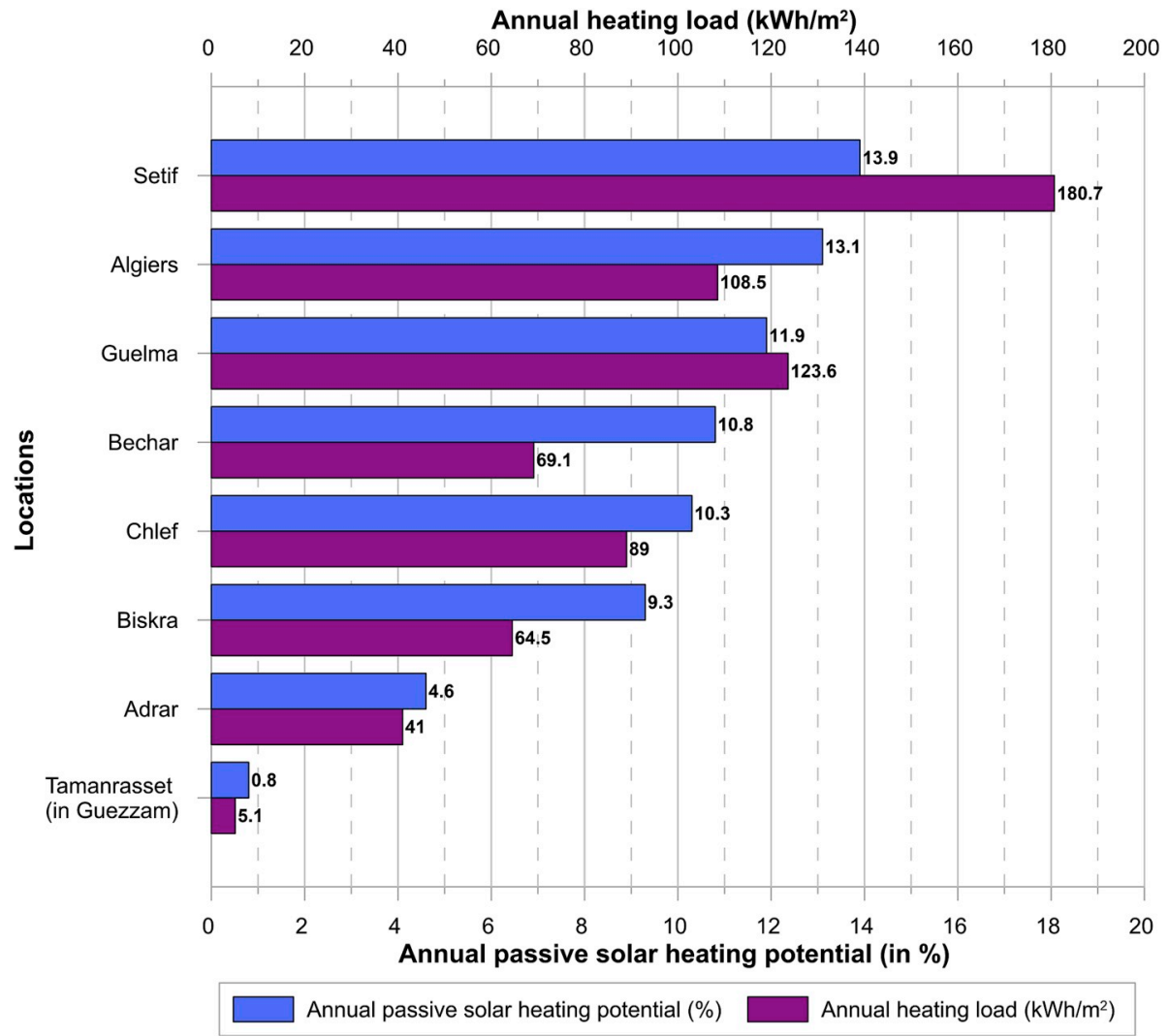

Fig. 15. Comparison between the annual passive heating potential (\%) and annual heating load $\left(\mathrm{kWh} / \mathrm{m}^{2}\right)$. 


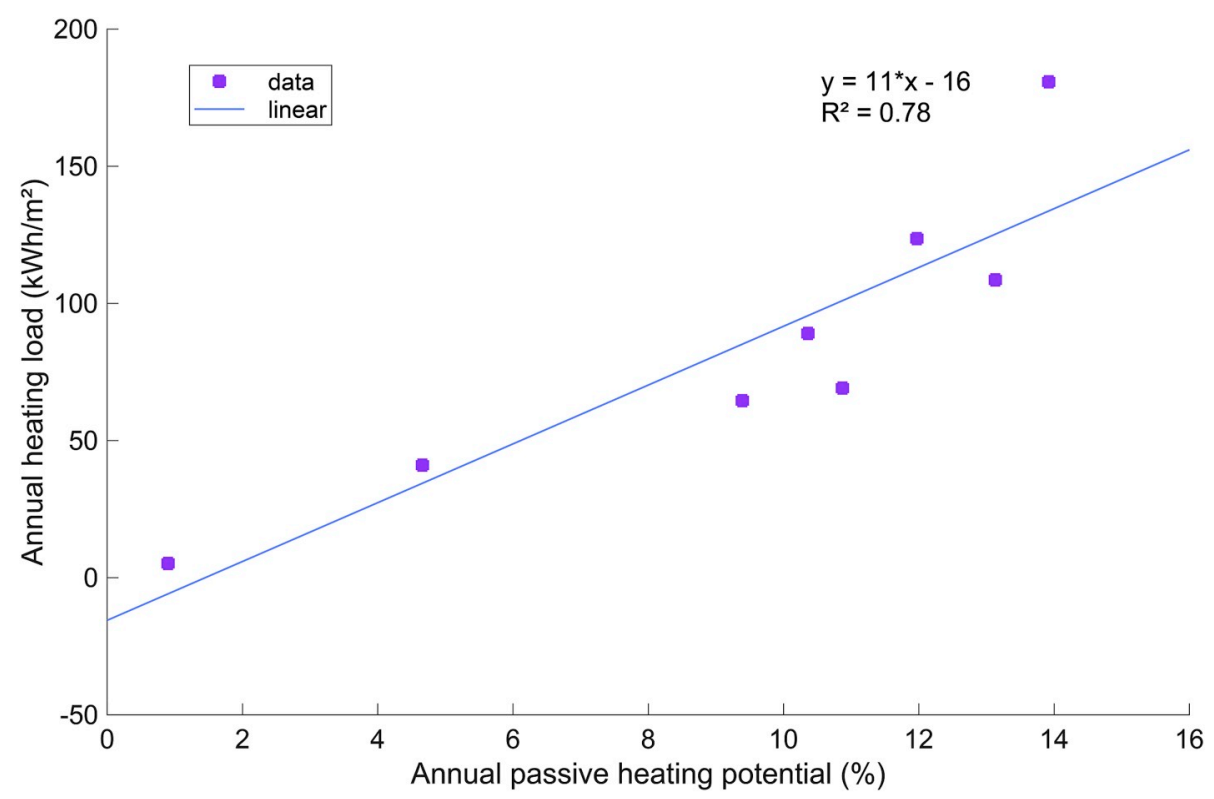

Fig. 16. Linear regression of the annual passive heating potential (\%) and annual heating load $\left(\mathrm{kWh} / \mathrm{m}^{2}\right)$.

The direct evaporative cooling represents the most effective strategy in the south of Algeria (Zones D and D') because the climate in the south is hot and dry (warm climate with very high temperatures during summer). The evaporative cooling potential exceeds $50 \%$. In addition, the direct evaporative cooling potential of the climate increases as the location geographically changes from the north towards the south of Algeria. The evaporative cooling potential is very low $(<4 \%)$ in the north (Zones $\mathrm{A}$ and $\mathrm{B}$ ) because these zones are exposed to the sea. However, these zones have the highest natural ventilation potential.

With respect to the passive heating potential, there is a significant difference between the potential estimation and calculation of the heating needs for Setif and Guelma. Our results indicate that the difference of the bioclimatic potential between stations in the same zone is significant although some locations are in the same climate zone (see Table 8). Our bioclimatic analysis results regarding the passive heating potential are listed below:

- The annual heating load calculation indicates that Setif has the highest heating load requirements due to its geographical location and altitude.

- Setif is followed by Algiers, Guelma, and Chlef, which form a group with similar heating load requirements.

- Bechar, Biskra, and Adrar benefit slightly less from passive heating.

- Tamanrasset is an extreme, where passive heating is the least effective because Tamanrasset is influenced by solar irradiation (see Fig. 15 and Table 8).
- The heating loads in the south represent $30 \%$ of the cooling loads. In contrast, the cooling loads in the north represent $11 \%$ of the heating loads, which agrees with the results obtained by Ghedamsi et al. (2016) [36], Kharchi et al. (2012) [52], and Belkacem et al. (2017) [53].

\subsection{Strength and limitations of the study}

The strength of the study relates to the use of a recent approach that combines simple chart-based bioclimatic analysis with simulation based advanced building performance analysis. The study uses high-quality data based on a recently compiled climatic dataset for Algerian weather stations. We believe that this recent approach, which was already used by Kumar et al. (2016) and Kishore et al. (2018) [16,17] and resembles similar approaches of Attia et al. (2019) [8], Pajek et al. (2018) [12], and Ali-Toudert et al. (2017) [37], benefits from the abundance of weather station data, advancements of simulation approaches and computational power, and advancement of the definition of adaptive comfort standards for hot climates. Our study is the first study that provides an accurate estimation of the bioclimatic potential for the whole country of Algeria in contrast to previous research (Ali-Toudert et al. [37]) that focused on specific climate zones of Algeria.

The quantification of the effectiveness of the bioclimatic strategies based on recent weather provided insights into the bioclimatic design potential for the six climatic zones of Algeria. Based on the use of the calibrated simulation model, reliable results could be obtained

Table 8

Summary of the findings.

\begin{tabular}{|c|c|c|c|c|c|c|c|c|c|}
\hline \multicolumn{2}{|c|}{ Climate Zone } & A & B & $\mathrm{B}^{\prime}$ & $\mathrm{C}$ & $\mathrm{D}$ & $\mathrm{D}$ & $\mathrm{D}$ & $\mathrm{D}^{\prime}$ \\
\hline \multicolumn{2}{|c|}{ Representative location } & Algiers & Guelma & Chlef & Setif & Biskra & Bechar & Tamanrasset (in Guezzam) & Adrar \\
\hline \multirow[t]{3}{*}{ Estimation } & Annual passive cooling potential (\%) & 21.9 & 17.8 & 29.4 & 21.5 & 39 & 46.7 & 60 & 53.9 \\
\hline & Annual passive solar heating potential (\%) & 13.1 & 11.9 & 10.3 & 13.9 & 9.3 & 10.8 & 0.8 & 4.6 \\
\hline & Annual cumulative comfort potential (\%) & 57.1 & 48.4 & 67.7 & 53.9 & 74.8 & 81.4 & 79.4 & 82.4 \\
\hline \multirow[t]{3}{*}{ Simulation } & Annual cooling load $\left(\mathrm{kWh} / \mathrm{m}^{2}\right)$ & 9.9 & 13.3 & 32.8 & 6.1 & 75.3 & 65.8 & 163.8 & 119.8 \\
\hline & Annual heating load $\left(\mathrm{kWh} / \mathrm{m}^{2}\right)$ & 108.5 & 123.6 & 89 & 180.7 & 64.5 & 69.1 & 5.1 & 41 \\
\hline & Annual simulated discomfort hours (\%) & 57.6 & 62.7 & 67.7 & 66.6 & 75.2 & 72.2 & 72.1 & 74.1 \\
\hline
\end{tabular}


regarding the thermal building performance and associated consequences of active heating and cooling system requirements.

On the other hand, this study has several limitations. Our reference case does not represent different housing typologies and is not adapted to the climate of each climatic zone. In addition, the calibration period of the simulation model is only one week for indoor temperatures and one year for electricity readings using a manual trial-and-error-based calibration approach. The study could have benefited from a longer monitoring period (three to five years) and an automated calibration using annual hourly data. However, we conducted our study using the best available data.

\subsection{Implications for the practice and future research}

The study results help to identify which bioclimatic design strategy is the most effective in each climate zone. We believe that architects and building engineers can apply our findings to their design concepts in early design stages to improve the indoor thermal comfort using passive design solutions. The presented tables and figures allow designers to apply adequate bioclimatic design strategies and evaluate the need for active systems in each climate zone using an adaptive comfort model that is suitable for the hot climate of Algeria. Another important implication of our study is that it calls for the creation of a new bioclimatic comfort map with more representative weather stations. Our study confirms that the current climatic classification of Algeria is obsolete. The National Building Efficiency Standard of Algeria must be updated. Therefore, we believe that the engagement with code officials to adopt and implement our findings and recommendations will anchor the impact of our study in the professional practice of building energy efficiency. Future research should focus on investigating the thermal comfort in each climatic zone of Algeria and developing climate specific design recommendations.

\section{Conclusion}

The bioclimatic potential of the six climate zones, including eight cities of Algeria, was calculated and compared using psychrometric charts and building performance simulations. A monitoring-based simulation model was created and calibrated for a reference case including eight Algerian cities. Despite the strong correlation between both bioclimatic potential analysis approaches (psychrometric chartbased and simulation-based), the results indicate a contradictions of bioclimatic potential estimations in several heating-dominated cities such as Setif, Guelma, and cooling dominated cities such as Tamanrasset. Therefore, our study findings indicate the misleading nature of psychrometric-based bioclimatic potential analysis in all cooling-dominated cities and all heating dominated cities. Overall, Algerian cities can be classified into two major categories including cooling- or heating-dominated cities. The percentage of average discomfort hours in Algerian households across all climatic zones is $60 \%$. Evaporative cooling is the most effective bioclimatic design strategy in Algeria, accounting for $60 \%$ of the hours annually in cooling-dominated cities due to their arid nature. Passive solar heating is the most effective bioclimatic design strategy in Algeria, accounting for $40 \%$ of the hours annually in heating-dominated cities due to their high altitudes. Our study confirms the need for a new bioclimatic zoning map for Algeria.
The following design recommendations characterize the bioclimatic conditions of each investigated city and provide guidance regarding the most effective passive design strategies based on Tables 1 and 5:

1. Algiers has a subtropical Mediterranean climate with dry summers. Natural ventilation and direct evaporative cooling are the most effective during summer and passive solar heating is the most effective during winter.

2. Guelma has a Midetereanan climate and is moderately rainy with colder and longer winters than those on the coast with hot and less humid summers. Natural ventilation and passive solar heating are effective in summer and winter, respectively.

3. Chlef has a subhumid and Mediterranean climate with cold winters and hot summers. The cooling period is long, accounting for $56 \%$ of the annual hours. Natural ventilation is the most effective during summer, followed by direct evaporative cooling. In winter, passive solar heating is the most effective strategy.

4. Setif has a continental climate with hot dry summers and very cold dry winters. In winter, passive solar heating is the most effective. In summer, natural ventilation and direct evaporative cooling are the most effective.

5. Biskra has an arid climate with the high temperature disparity between day and night as well as between summer and winter. Direct evaporative cooling is the most effective strategy in the summer, followed by natural ventilation. However, passive solar heating is the most effective in the winter. The duration of the heating period is equal to that of the cooling period.

6. Bechar has an arid climate with a high temperature disparity between day and night as well as between summer and winter. Direct evaporative cooling is the most effective strategy in summer, followed by natural ventilation. However, passive solar heating is needed in winter. The duration of the heating period is the same as that of the cooling period.

7. Adrar has an arid climate with dry and very hot summers and very cold winters. Direct evaporative cooling is the most effective strategy in summer, followed by natural ventilation. However, passive solar heating is needed in winter. The heating period accounts for $52 \%$ of the annual hours.

8. Tamanrasset has very dry or hyperarid and sunny climate all year round. Direct evaporative cooling is the most effective strategy in summer and passive solar heating is unnecessary in winter.

\section{Acknowledgements}

We acknowledge the Algerian Ministry of Higher Education for providing a funded internship to the first author at the University of Liege through the "Programme National Exceptionnel (PNE)" under file no. 23/enseignant/Belgique/2018-2019.

This article is published with the financial support of the Fonds de la Recherche Scientifique-FNRS.

We would like to acknowledge the LACOMOFA Laboratory, University of Biskra, and the Sustainable Building Design (SBD) Laboratory at the University of Liege for the use of the monitoring equipment in this research and valuable support during the experiments and data analysis. Also, the authors thank Arch. Moussi H. for providing the technical drawings of the case study building. 


\section{Appendix A}

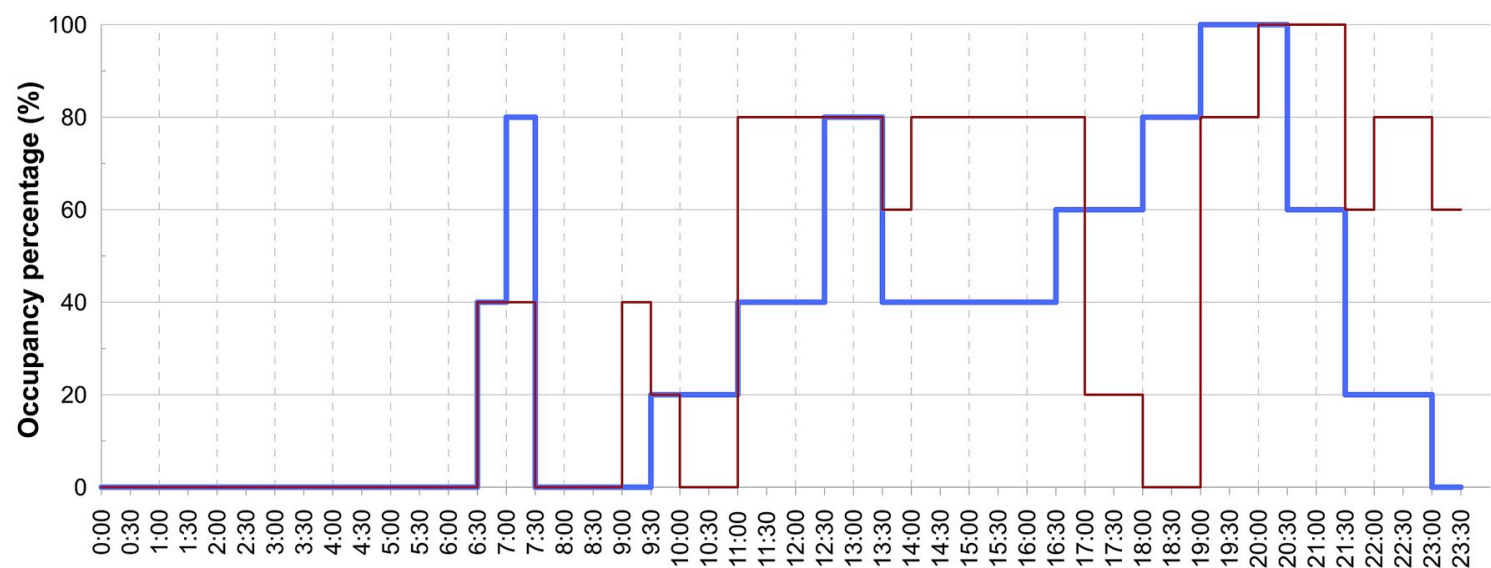

Time (hours)

- Winter occupancy schedule (\%) — Summer occupancy schedule (\%)

(a)

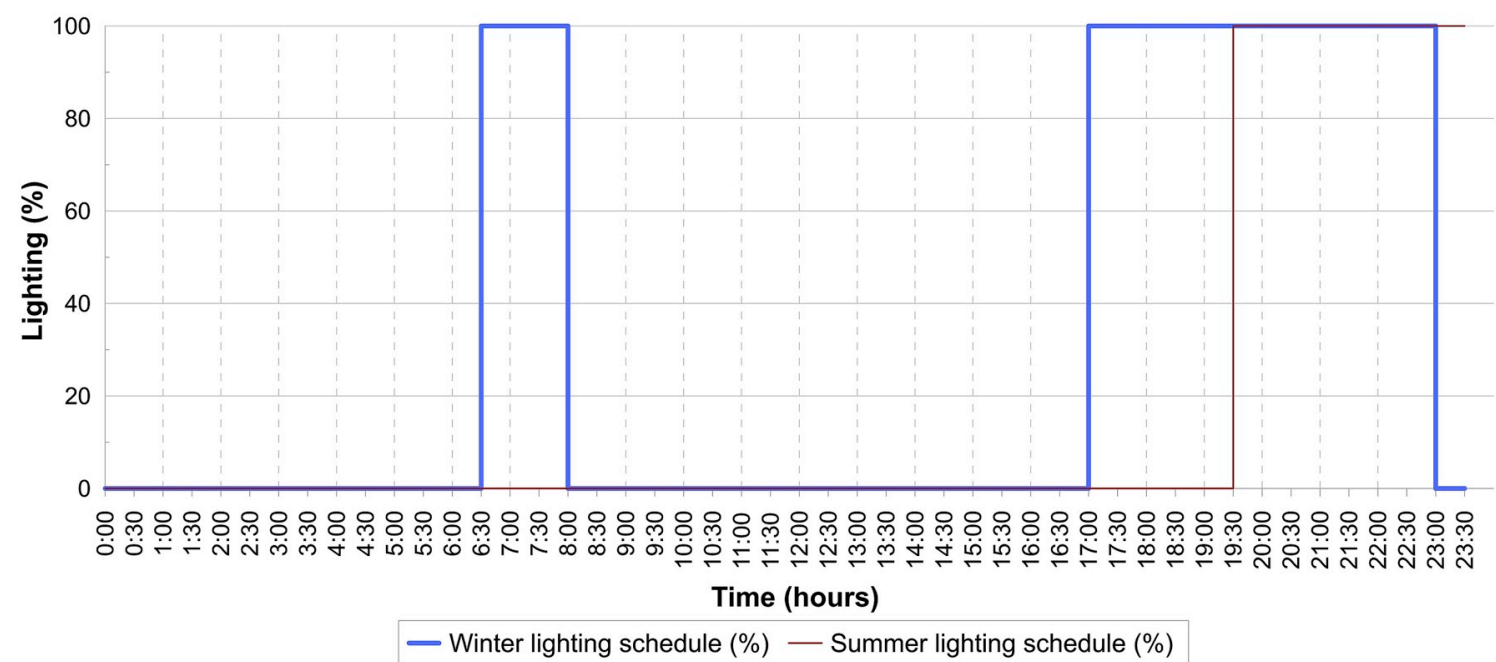

(b)

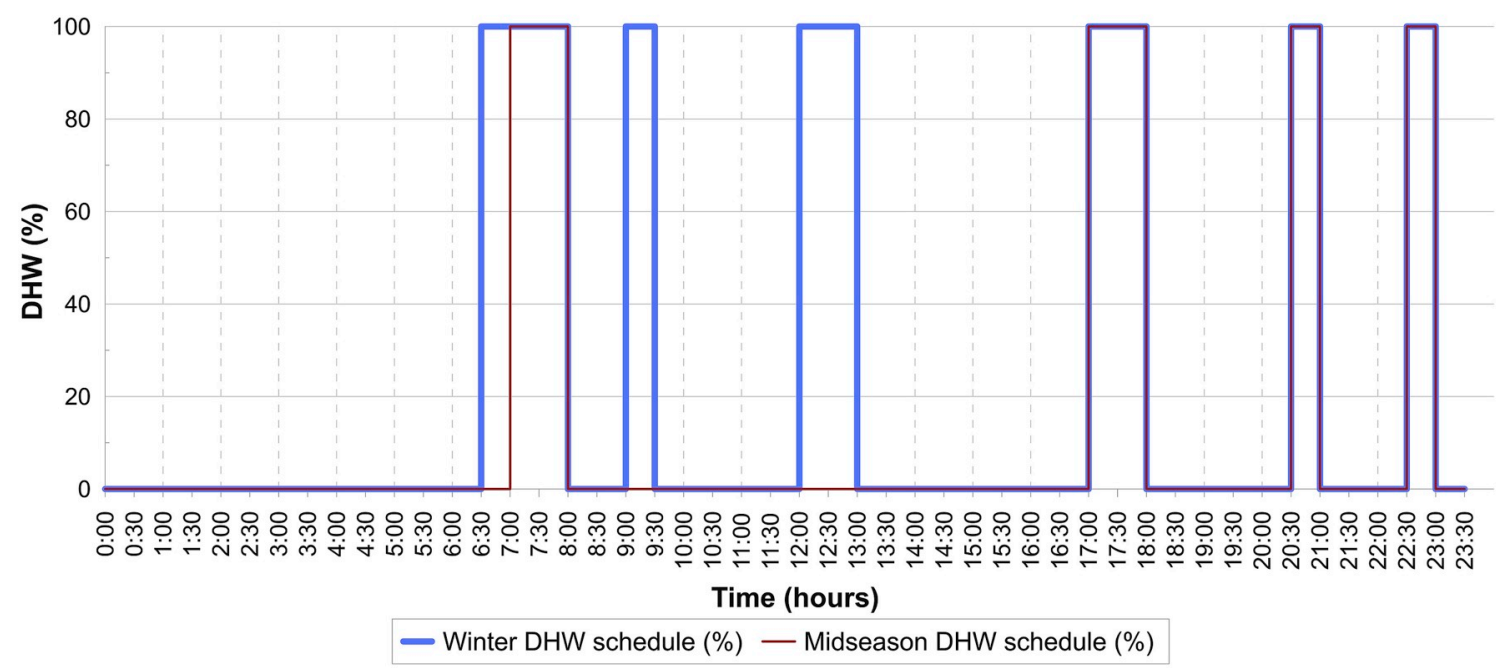

(c)

Fig. A. Winter and summer schedules of the simulated building model. (a) living room occupancy, (b) living room lighting, and (c) DWH. 


\section{Appendix B. Supplementary data}

Supplementary data to this article can be found online at https://doi.org/10.1016/j.buildenv.2019.106271.

\section{References}

[1] S. Attia, Net Zero Energy Buildings (NZEB): Concepts. Frameworks and Roadmap for Project Analysis and Implementation, Elsevier, 978-0128124611, 2018, https:// doi.org/10.1016/c2016-0-03166-2.

[2] F. Manzano-Agugliaro, F.G. Montoya, A. Sabio-Ortega, A. García-Cruz, Review of bioclimatic architecture strategies for achieving thermal comfort, Renew. Sustain. Energy Rev. 49 (2015) 736-755.

[3] R.J. de Dear, T. Akimoto, E.A. Arens, G. Brager, C. Candido, K.W.D. Cheong, ... J. Toftum, Progress in thermal comfort research over the last twenty years, Indoor Air 23 (6) (2013) 442-461.

[4] S. Carlucci, L. Bai, R. de Dear, L. Yang, Review of Adaptive Thermal Comfort Models in Built Environmental Regulatory Documents, Building and Environment, 2018.

[5] 1 November 2018, A. Pérez-Fargallo, J.A. Pulido-Arcas, C. Rubio-Bellido, M. Trebilcock, B. Piderit, S. Attia, Development of a new adaptive comfort model for low income housing in the central-south of Chile, Energy Build. 178 (2018) 94-106 0378-7788 https://doi.org/10.1016/j.enbuild.2018.08.030.

[6] Y. Chen, Z. Tong, A. Malkawi, Investigating natural ventilation potentials across the globe: regional and climatic variations, Build. Environ. 122 (2017) 386-396.

[7] GhR. Roshan, M. Farrokhzad, S. Attia, Defining thermal comfort boundaries for heating and cooling demand estimation in Iran's urban settlements, Build. Environ. 121 (2017) 168-189 0360-1323 https://doi.org/10.1016/j.buildenv.2017.05.023.

[8] S. Attia, T. Lacombe, H.T. Rakotondramiarana, F. Garde, G.R. Roshan, Analysis tool for bioclimatic design strategies in hot humid climates, Sustain. Cities Soc. 46 (2019), https://doi.org/10.1016/j.scs.2018.11.025 April 2019. p 88-24.

[9] Autodesk, Ecotect Weather Tool. Version 8, (2019).

[10] M. Milne, R. Liggett, R. Al-Shaali, Climate consultant 3.0: a tool for visualizing building energy implications of climates, Proceedings of the Solar Conference, vol. $1,2007$.

[11] M. Milne, Climate Consultant V6. 0, (2016).

[12] L. Pajek, M. Košir, Implications of present and upcoming changes in bioclimatic potential for energy performance of residential buildings, Build. Environ. 127 (2018) 157-172.

[13] A. Krishan (Ed.), Climate Responsive Architecture: a Design Handbook for Energy Efficient Buildings, Tata McGraw-Hill Education, 2001.

[14] S. Visitsak, J.S. Haberl, An Analysis of Design Strategies for Climate-Controlled Residences in Selected Climates, (2004).

[15] June 2012, S. Attia, E. Gratia, A. De Herde, J. Hensen, Simulation-based decision support tool for early stages of zero-energy building design, Energy Build. 49 (2012) 2-15, https://doi.org/10.1016/j.enbuild.2012.01.28 0378-7788.

[16] S. Kumar, J. Mathur, S. Mathur, M.K. Singh, V. Loftness, An adaptive approach to define thermal comfort zones on psychrometric chart for naturally ventilated buildings in composite climate of India, Build. Environ. 109 (11) (2016) 135-153.

[17] N. Kishore, J. Rekha, A Bioclimatic Approach to Develop Spatial Zoning Maps for Comfort. Passive Heating and Cooling, (2018).

[18] D. Watson, K. Labs, Climatic Building Design: Energy- Efficient Building Principles and Practice, McGraw-Hill. Inc., New York. NY, 1983.

[19] D.P. Gatley, Psychrometric chart celebrates 100th anniversary, ASHRAE J. 46 (11) (2004) 16.

[20] V. Olgyay, Design with Climate: Bioclimatic Approach to Architectura Regionalism-New, and expanded Edition, Princeton university press, 2015.

[21] M. DeKay, G.Z. Brown, Sun. Wind. And Light: Architectural Design Strategies, John Wiley \& Sons, 2013.

[22] M. Milne, B. Givoni, Architectural design based on climate, in: D. Watson (Ed.), Energy Conservation through Building Design, McGrawHill. Inc., New York. NY, 1979, pp. 96-113.

[23] M. Milne, S. Yoshikawa, SOLAR-5: an interactive computer-aided passive solar design system, Proceedings of the 3rd Annual Passive Solar Conference. AS/ISES San Jose. CA. January, 1979.

[24] S.V. Szokolay, Climate analysis based on the psychrometric chart, Int. J. Ambient Energy 7 (4) (1986) 171-182.

[25] P. La Roche, R. Liggett, Very simple design tools: a web based assistant for the design of climate responsive buildings, Architect. Sci. Rev. 44 (4) (2001) 437-448.

[26] A.H.A. Mahmoud, An analysis of bioclimatic zones and implications for design of outdoor built environments in Egypt, Build. Environ. 46 (3) (2011) 605-620.

[27] L. Guan, M. Bennett, J. Bell, Evaluating the potential use of direct evaporative cooling in Australia, Energy Build. 108 (2015) 185-194.

[28] M.M. Osman, H. Sevinc, Adaptation of Climate-Responsive Building Design
Strategies and Resilience to Climate Change in the Hot/Arid Region of Khartoum. Sudan, Sustainable Cities and Society, 2019, p. 101429.

[29] M.C. Katafygiotou, D.K. Serghides, Bioclimatic chart analysis in three climate zones in Cyprus, Indoor Built Environ. 24 (6) (2015) 746-760.

[30] L. Pajek, M. Košir, Can building energy performance be predicted by a bioclimatic potential analysis? Case study of the Alpine-Adriatic region, Energy Build. 139 (2017) 160-173.

[31] A.S.F. Ahmed, K.M.M.K. Khan, A.A.M.T. Oo, R.M.G. Rasul, Selection of suitable passive cooling strategy for a subtropical climate, Int. J. Mech. Mater. Eng. 9 (1) (2014) 14.

[32] GhR. Roshan, A.A. Ghanghermeh, S. Attia, Determining new threshold temperatures for cooling and heating degree day index of different climatic zones of Iran, Renew. Energy 101 (2016) 156-167 ISSN 0960-1481 https://doi.org/10.1016/j. renene.2016.08.053.

[33] P. De Wilde, Building Performance Analysis, John Wiley \& Sons, 2018.

[34] M. Khoukhi, N. Fezzioui, Thermal comfort design of traditional houses in hot dry region of Algeria, Int. J. Energy Environ. Eng. 3 (1) (2012) 5.

[35] K. Imessad, L. Derradji, N.A. Messaoudene, F. Mokhtari, A. Chenak, R. Kharchi, Impact of passive cooling techniques on energy demand for residential buildings in a Mediterranean climate, Renew. Energy 71 (2014) 589-597.

[36] R. Ghedamsi, N. Settou, A. Gouareh, A. Khamouli, N. Saifi, B. Recioui, B. Dokkar, Modeling and forecasting energy consumption for residential buildings in Algeria using bottom-up approach, Energy Build. 121 (2016) 309-317.

[37] F. Ali-Toudert, J. Weidhaus, Numerical assessment and optimization of a low-energy residential building for Mediterranean and Saharan climates using a pilot project in Algeria, Renew. Energy 101 (2017) 327-346.

[38] N.K. Khambadkone, R. Jain, A bioclimatic analysis tool for investigation of the potential of passive cooling and heating strategies in a composite Indian climate, Build. Environ. 123 (2017) 469-493.

[39] DTRC3-2, Thermal regulation of residential buildings e calculating methods for determining building heat losses, CNERIB, Algiers, 1997 [in French] www.cnerib. edu.dz.

[40] M.R. Yaiche, A. Bouhanik, S.M.A. Bekkouche, A. Malek, T. Benouaz, Revised solar maps of Algeria based on sunshine duration, Energy Convers. Manag. 82 (2014) 114-123.

[41] (ClimateOne 2019), http://climate.onebuilding.org.

[42] N. Fezzioui, M. Khoukhi, Z. Dahou, K. Aït-Mokhtar, S. Larbi, Bioclimatic architectural design of ksar de kenadza: south-west area of Algeria hot and dry climate, Architect. Sci. Rev. 52 (3) (2009) 221-228.

[43] B. Givoni, Comfort. climate analysis and building design guidelines, Energy Build. 18 (1) (1992) 11-23.

[44] L. Derradji, K. Imessad, M. Amara, F.B. Errebai, A study on residential energy requirement and the effect of the glazing on the optimum insulation thickness, Appl. Therm. Eng. 112 (2017) 975-985.

[45] DOE, EnergyPlus Energy Simulation Software, Energy Efficiency \& Renewable Energy. US Department of Energy, 2019 Available at: http://app1.eere.energy.gov/ buildings/energyplus/energyplus_about.Cfm, Accessed date: 25 March 2019.

[46] M.D. Colton, P. MacNaughton, J. Vallarino, J. Kane, M. Bennett-Fripp, J.D. Spengler, G. Adamkiewicz, Indoor air quality in green vs conventional multifamily low-income housing, Environ. Sci. Technol. 48 (14) (2014) 7833-7841.

[47] A.C.K. Lai, K.W. Mui, L.T. Wong, L.Y. Law, An evaluation model for indoor environmental quality (IEQ) acceptance in residential buildings, Energy Build. 41 (9) (2009) 930-936.

[48] ASHRAE, Guideline 14-2002: Measurement of Energy and Demand Savings, ASHRAE, Atlanta. Georgia, 2002.

[49] DTRC3-4, Airconditioning - Calculating Methods for Determining Building Heat Gains, CNERIB, Algiers, 1997 [in French] www.cnerib.edu.dz.

[50] ASHRAE, ANSI/ASHRAE Standard 55-Thermal Environmental Conditions for Human Occupancy, American Society of Heating. Refrigerating and AirConditioning Engineers (ASHRAE), Atlanta. GA. USA, 20172017.

[51] S. Sahabi Abed, A. Matzarakis, Seasonal regional differentiation of human thermal comfort conditions in Algeria, Adv. Meteorol. 2017 (2017).

[52] R. Kharchi, B. Benyoucef, F. Mokhtari, K. Imessad, Dynamic simulation of both thermal and energetic behavior for dwellings located in Algiers, J. Earth Sci. Clim. Chang. 3 (122) (2012) 2.

[53] N. Belkacem, L. Loukarfi, M. Missoum, H. Naji, A. Khelil, M. Braikia, Assessment of energy and environmental performances of a bioclimatic dwelling in Algeria's North, Build. Serv. Eng. Technol. 38 (1) (2017) 64-88. 